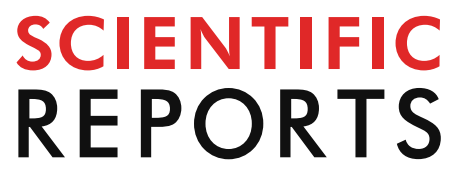

natureresearch

Check for updates

\title{
Osteopontin regulates biomimetic calcium phosphate crystallization from disordered mineral layers covering apatite crystallites
}

\author{
Taly lline-Vul' ${ }^{1}$, Raju Nanda' ${ }^{1}$, Borja Mateos ${ }^{2}$, Shani Hazan ${ }^{1}$, Irina Matlahov ${ }^{1}$, \\ Ilana Perelshtein ${ }^{1}$, Keren Keinan-Adamsky ${ }^{1}$, Gerhard Althoff-Ospelt ${ }^{3}$, Robert Konrat ${ }^{2}$ \& \\ Gil Goobes $^{1 \bowtie}$
}

Details of apatite formation and development in bone below the nanometer scale remain enigmatic. Regulation of mineralization was shown to be governed by the activity of non-collagenous proteins with many bone diseases stemming from improper activity of these proteins. Apatite crystal growth inhibition or enhancement is thought to involve direct interaction of these proteins with exposed faces of apatite crystals. However, experimental evidence of the molecular binding events that occur and that allow these proteins to exert their functions are lacking. Moreover, recent high-resolution measurements of apatite crystallites in bone have shown that individual crystallites are covered by a persistent layer of amorphous calcium phosphate. It is therefore unclear whether non-collagenous proteins can interact with the faces of the mineral crystallites directly and what are the consequences of the presence of a disordered mineral layer to their functionality. In this work, the regulatory effect of recombinant osteopontin on biomimetic apatite is shown to produce platelet-shaped apatite crystallites with disordered layers coating them. The protein is also shown to regulate the content and properties of the disordered mineral phase (and sublayers within it). Through solid-state NMR atomic carbon-phosphorous distance measurements, the protein is shown to be located in the disordered phases, reaching out to interact with the surfaces of the crystals only through very few sidechains. These observations suggest that non-phosphorylated osteopontin acts as regulator of the coating mineral layers and exerts its effect on apatite crystal growth processes mostly from afar with a limited number of contact points with the crystal.

Calcium phosphate mineralization processes are key to constructing well-organized mechanically viable structures in tissues like bone ${ }^{1,2}$, tooth enamel, dentin and cementum. One of the more complex mineralized tissues is no doubt bone. Bone can take different densities and compositions of minerals depending on the mechanical task it is destined to perform and the maturation stage of the tissue. Assembled collagen fibers adopt various ordered and disordered architectures depending on their location in the bone matrix and the type of bone ${ }^{3-7}$, providing with the scaffold for calcium phosphate to precipitate and transform into apatite ${ }^{8}$. A substantial part of bone mineralization occurs through apatite precipitation inside and around collagen fibrils ${ }^{9,10}$. Biomimetic mineralization of collagen involves precipitation of the precursor inorganic ions in the presence of polyaspartate which leads to formation of apatite ${ }^{11-13}$. This polyelectrolyte is used as model molecule for the acidic noncollagenous proteins (NCPs) in bone, known to regulate mineral formation ${ }^{14-16}$. The interplay of collagen, NCPs and other constituents such as water, citrate ions, glycosaminoglycans (GAG) in forming tight interfaces that provide bone with its exquisite mechanical properties is the subject of extensive ongoing investigations ${ }^{17}$ and few controversies ${ }^{18,19}$. Recent work has shown that collagen functions in synergy with polyaspartate as an inhibitor of mineral nucleation to actively control mineralization. In another work, GAGs were shown to interact directly with the mineral phase in bones ${ }^{20}$. Other studies suggested that collagen is able to initiate the mineralization

\footnotetext{
${ }^{1}$ Department of Chemistry, Bar Ilan University, 5290002 Ramat Gan, Israel. ${ }^{2}$ Max F. Perutz Laboratories, Department of Computational and Structural Biology, University of Vienna, 1030 Vienna, Austria. ${ }^{3}$ Solid-State NMR Application, Bruker Biospin $\mathrm{GmbH}$, Rheinstetten, Germany. ${ }^{凶}$ email: gil.goobes@biu.ac.il
} 
process without active involvement of other biomolecules ${ }^{9}$, and emphasized the role of water and citrate ions in orienting and spacing out apatite crystal platelets ${ }^{21}$.

\section{Biological activity of non-colagenous proteins}

The specific functions of many NCPs remain elusive and more so the way these activities fit into an integrative picture of inorganic material design in bone. Their unusual primary structure, with segments that are nonhomologous with other known proteins, may indicate diverse functions, some of which still uncovered. Many of the NCPs were shown to be directly involved in control of hydroxyapatite (HAP) crystallization ${ }^{22}$; some can inhibit crystal nucleation or growth while others promote and speed up the process ${ }^{23}$. In addition, non-collagenous proteins impart important functions in cell signaling and recruitment and in maintaining ion homeostasis. Their regulatory capabilities over bone mineral and bone cell activities, indicates that they may be influencing bone mineralization in more than one pathway.

As different NCPs may perform complementary functions in mineralization, there is a need to compare the activity of a range of NCPs in bone-mimetic and enamel-mimetic mineralization ${ }^{24}$ in vitro and to infer in atomic detail the changes they may impose on the different mineral phases that are precipitated. Such studies are also extremely important to deciphering mineralization in other organisms ${ }^{25}$. Recently, we have studied the regulatory effect on the in vitro crystallization of bone-mimetic apatite of two bone-associated polypeptides. Osteocalcin, unmodified posttranslationally ${ }^{26}$ (umOC) and ON29, a peptide from osteonectin's mineral binding domain ${ }^{27}$ exhibited markedly different effects on the process of crystallization. Apart from their disparate effects on the morphology and crystallinity of apatite, we could show that the two biomolecules also intervened with the thickness and composition of the amorphous mineral layer, coating the apatite crystallites; ON29 induced thickening of this layer, while OC promoted the reverse. These studies revealed a new partially ordered mineral phase interconnecting the crystalline and amorphous phases we termed the "inter-phase". The existence of such intermediate mineral phase alleviates the stringent transition from a completely disordered hydrated phase to a highly ordered core crystalline phase. ON29 and umOC co-precipitated with the mineral were capable of changing the content of $\mathrm{HPO}_{4}{ }^{2-}$ ions and water molecules in the hydrated layer as well ${ }^{26-29}$. These findings open new questions regarding the capabilities possessed by non-collagenous proteins, for regulating and modifying the mineral phases via organic-inorganic interactions.

\section{Osteopontin biological activity}

One of the extensively studied NCPs is osteopontin (OPN), named for its role as a bridge between cells and minerals. OPN is a bone matrix glycoprotein found in bone and teeth. The protein is a large intrinsically disordered protein (IDP) highly enriched in acidic sidechains; a quarter of its sequence contains acidic aspartic or glutamic residues. The protein is also extensively phosphorylated post-translationally as part of its functional regulation $^{30-32}$. The protein is classified as a matricellular cytokine ${ }^{33,34}$ serving as an important factor in bone remodeling and in bone formation under mechanical stress ${ }^{35}$. However, the exact function of OPN in the mineralization process is still unclear as its activity in higher tasks such as cell signaling were not completely worked out yet ${ }^{36,37}$. OPN and other NCPs are members of the SIBLING family (small integrin binding ligand N-linked glycoproteins) which contain the ASARM motif (the acidic serine-and aspartate-rich) ${ }^{30}$. Phosphorylated ASARM peptides are known to bind hydroxyapatite crystals and inhibit extracellular matrix mineralization ${ }^{38}$. This inhibition is regulated by the protease PHEX ${ }^{39,40}$ which can cleave OPN to fragments so small that they retain no activity in mineral regulation anymore.

The effect of the phosphorylation of OPN peptides on calcium phosphate mineral formation, growth, and mineralization inhibition was examined by several groups ${ }^{17,41-43}$. The protein binds divalent cations with high affinity in solution ${ }^{44}$ and may act as an inhibitor and as a nucleator of apatite, depending on its concentration, the state of phosphorylation and the abundance of acidic amino acids along its sequence ${ }^{23,32,45}$. A phosphorylated synthetic short peptide derived from OPN was shown to inhibit HAP growth more effectively than the very acidic DDDDDD peptide ${ }^{46}$. The $\mathrm{pH}$ used in these measurements was set to physiological value (pH 7.4) at which HAP solubility was higher thus promoting formation of other calcium-phosphate phases. A recent work has challenged the relation between the phosphorylation state in OPN and its calcium binding ability ${ }^{37,44}$.

\section{Structural features of osteopontin}

Early studies using NMR showed that OPN, along with other SIBLING proteins, has a flexible structure in solution ${ }^{47}$. At about the same time, other NCPs were suggested to be intrinsically disordered in solution ${ }^{48,49}$, leading to a new paradigm relating high conformational flexibility to regulation capabilities of mineral crystal growth through motions ${ }^{36}$. Recent NMR analysis confirmed that OPN is intrinsically disordered in solution ${ }^{50-52}$. Using ${ }^{13} \mathrm{C}$ secondary shifts, local secondary structure elements were identified having reduced conformational flexibility. The correlation between dynamic heterogeneity along the protein backbone and deviations from random coil chemical shifts provided information of local structure motifs with motion-restricted residues suggesting stable local conformations. Analysis of the protein's meta-structure provided quantitative information about regional compactness and topology in the protein ${ }^{50}$. At the same time, the structures of the charged domains, noted as potential binding motifs to the mineral phase, are still challenging to determine experimentally ${ }^{47}$.

\section{Functions of osteopontin in bone mechanics}

The contribution of NCPs to mechanical viability of bone, acting as key interfacial constituents in organic-inorganic composite structure, was lately investigated ${ }^{53}$. Genetic knockout mice models were used in order to explore the role of OPN and osteocalcin (OC) proteins jointly and separately in bone toughness and in tissue response to micro cracking ${ }^{54}$. Bone fracture was shown to involve the formation of dilatation bands as a result of OC-OPN 

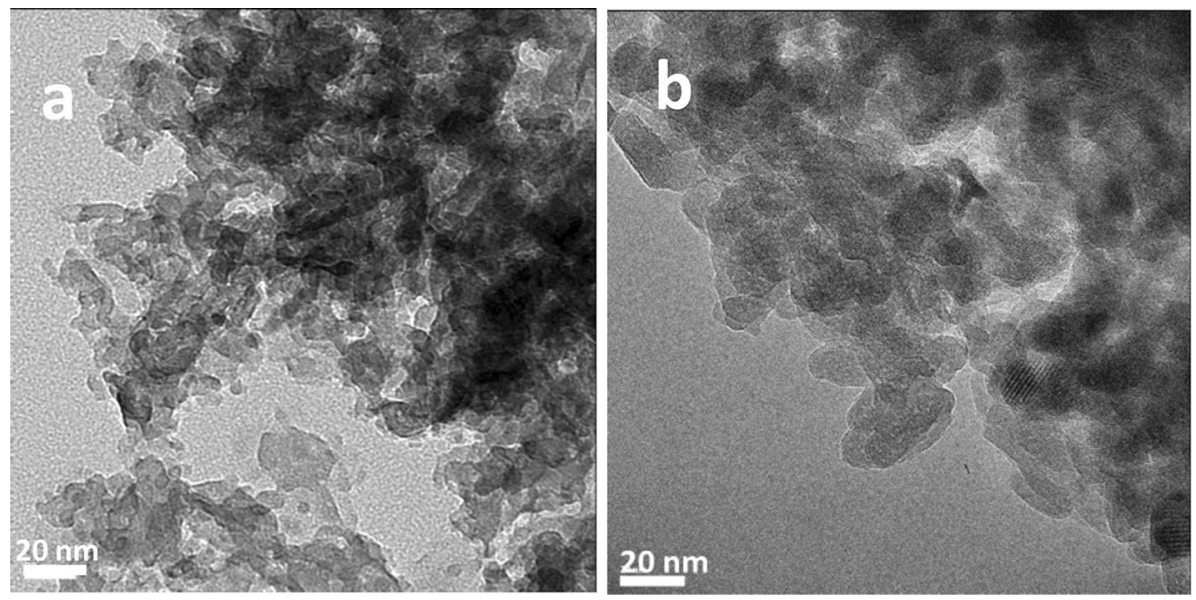

Figure 1. Platelet-shaped crystallites observed in the transmission electron micrographs of (a) HAP and (b) HAP.qOPN.

complex interaction. In that study, OPN was docked to extrafibrillar mineral via the linker protein OC and participated in greater energy dissipation upon mechanical load. The toughness of bone was shown to decrease dramatically in mice lacking OC, OPN or both. OPN deficiency alone led to a $30 \%$ decrease in mice femur fracture toughness and to a larger variability in calcium concentration in the bone ${ }^{53}$. The atomic details of the organic-inorganic interfaces in these genetic knockout bones were compared to wild-type bones by solid-state $\mathrm{NMR}^{55}$, showing some modulation in lysine/arginine residues and GAG/citrate molecules content at the interfaces. Evidently, fundamental analysis of the organic-mineral interface in the context of the entire tissue is still challenging and more so will be to identify subtle differences taking place during early mineralization event with OPN, though recent in vitro work reported changes to mineral ion clustering caused by the protein during crystallization $^{56}$.

\section{Mineral phases and osteopontin-mineral interface}

In the present study, the influence of a recombinant OPN comprising residues 45 to 264 of the quail Coturnix japonica on bone-like mineral formation was examined. Bone-mimetic apatite was crystallized in the presence of quail osteopontin (qOPN) under physiological temperature and using fixed $\mathrm{pH}$ conditions. The effect of the biomolecule on composition, phase, and morphology of the forming mineral were analyzed by solid-state NMR spectroscopy, powder X-ray diffraction (XRD), electron microscopy (EM), Brunauer-Emmet-Teller (BET) gas adsorption isotherms, inductively coupled plasma (ICP) and elemental analysis (EA).

The protein is shown to modulate the properties of the disordered mineral layers coating the core apatite crystallite. Relayed ${ }^{13} \mathrm{C}-{ }^{31} \mathrm{P}$ magnetization transfer NMR measurements indicate that the protein is closer to phosphates in the disordered layers than to phosphates in the core apatite phase, consistent with its prominent effect on the properties of this phase mostly. Direct proximity measurements from protein carbons to mineral phosphates further corroborate this, by indicating only few contact points between the protein and the apatite crystal surface.

\section{Results and discussion}

Electron microscopy, diffraction and surface area measurements. HRTEM images of HAP (a) and HAP.qOPN (b) are shown in Fig. 1. These images show that the morphology of individual crystallites is plate-like in both samples, reminiscent of the apatite crystallites in bone. The average plate size is $10-20 \mathrm{~nm}$ for apatite and 10-15 nm for apatite formed with qOPN. Electron diffraction analyses of crystallites from selected area of the two samples are shown in Figs. S1-S3, confirming that the crystallites are comprised of hexagonal hydroxyapatite.

Powder X-ray diffractograms of HAP (red) and HAP.qOPN (blue) are shown in Fig. S4. The reflection pattern of HAP.qOPN is showing slightly broader lines and lower $\mathrm{S} / \mathrm{N}$ ratio than HAP suggesting smaller crystallites were formed with the protein. Scherer analysis of the $25.9^{\circ}$ reflection width, accordingly, gave a crystallite size of $24( \pm 2) \mathrm{nm}$ for HAP and $20( \pm 2) \mathrm{nm}$ for HAP·qOPN. The crystallites size in the electron micrographs for both samples are in reasonable agreement with the Scherer analysis of the XRD results. The Scherer equation gives a crude upper boundary value of the crystallites size and is affected by factors such as non-uniform lattice distortions, grain surface relaxation, dislocations and instrumental peak profile. HRSEM images of HAP and HAP.qOPN are shown in Fig. 2. The crystallites appear denser in the HAP.qOPN image as they were more challenging to disperse in the presence of the protein. Brunauer-Emmet-Teller isotherms were used to record the specific surface area (SSA), of HAP $185( \pm 19) \mathrm{m}^{2} / \mathrm{g}$ and HAP.qOPN $99( \pm 10) \mathrm{m}^{2} / \mathrm{g}$. These values indicate lower surface is available for nitrogen adsorption in the mineral prepared with qOPN. 

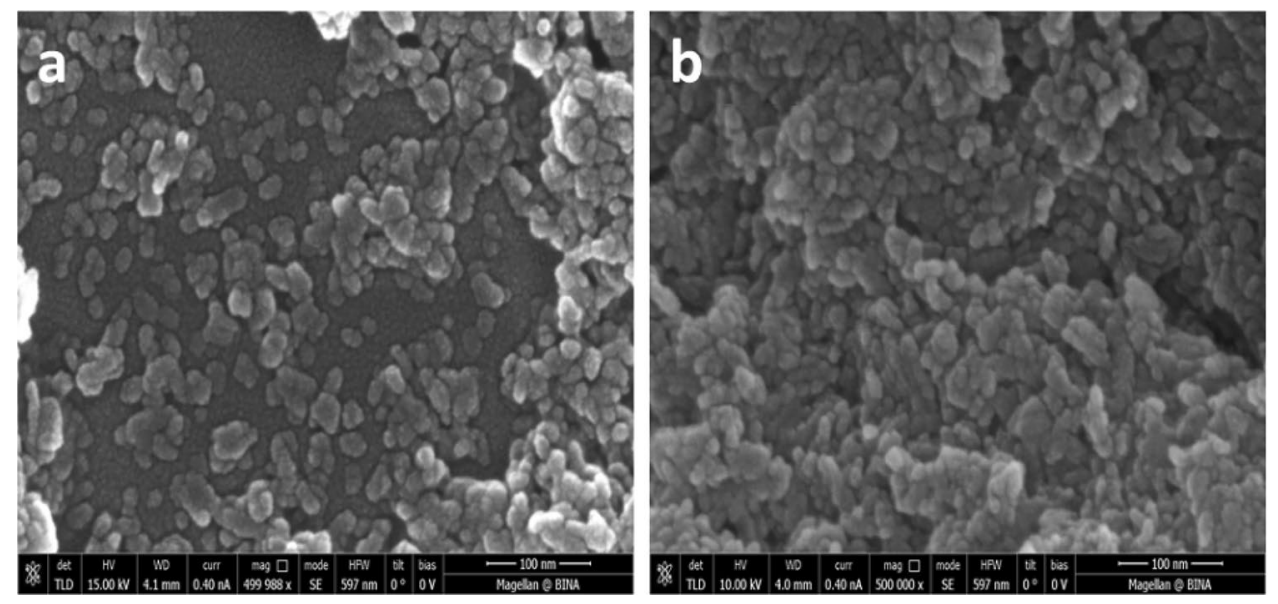

Figure 2. Agglutination of apatite particles observed from scanning electron micrographs of (a) HAP and (b) HAP·qOPN.

\begin{tabular}{|l|l|l|l|c|}
\hline & Nitrogen & Carbon & Hydrogen & Oxygen \\
\hline HAP & - & 1.13 & 1.39 & 9.71 \\
\hline HAP.qOPN & 2.21 & 7.79 & 1.81 & 14.24 \\
\hline
\end{tabular}

Table 1. Elemental analysis of HAP and HAP·qOPN (values reported in wt\%).

Elemental and thermogravimetric analysis. Inductively coupled plasma (ICP) analysis was performed to determine the bulk calcium to phosphate ratio. The measurements were carried out in several repeats and verified against commercial nano HAP from Sigma-Aldrich, which gave a value of 1.70 . The $\mathrm{Ca} / \mathrm{P}$ ratio measured for HAP without qOPN protein was 1.66 and the ratio for HAP·qOPN was 1.78 (the stoichiometric value for hydroxyapatite is 1.67).

Elemental analysis results of the two samples are summarized in Table 1 . HAP contains $1.1 \mathrm{wt} \%$ of carbon precipitating with mineral ions, indicating that under the conditions used some carbonates are incorporated into the apatite during synthesis from residual $\mathrm{CO}_{2}$ gas dissolved in the precipitation solution. Elemental analysis of HAP in the presence of the protein indicates that a substantial amount of the protein precipitates with the mineral. The $\mathrm{C} / \mathrm{N}$ ratio in HAP.qOPN is 3.52 (Table 1 ) which is higher than the calculated ratio for qOPN, 3.28 based on its sequence. The difference is attributed to incorporation of carbonate ions into the mineral during its formation, similarly to the HAP sample.

TGA analysis of HAP.qOPN (Fig. S5) shows that the protein constitutes 15\% weight of the complex ( $\sim 0.25 \mathrm{~mol} \%)$. Comparison of the normalized weight loss with temperature after accounting for slight differences in water evaporation in HAP.qOPN and in HAP is shown in Fig. S5. Combustion of the organic material is observed from $250{ }^{\circ} \mathrm{C}$ to $550^{\circ} \mathrm{C}$ followed by another weight decrease of $\sim 1.6 \%$ between $750{ }^{\circ} \mathrm{C}$ and $850{ }^{\circ} \mathrm{C}$. The sigmoidal shape of the weight loss curve during pyrolysis of the qOPN may suggest a cooperative process, putatively of desorption, that precedes combustion of the molecules. Differential thermal analysis, also shown in Fig. S5, indicates that pyrolysis of qOPN is maximal at a temperature of $350{ }^{\circ} \mathrm{C}$.

Solid state NMR analysis of the crystalline and disordered mineral phases. ${ }^{31} P$ direct polarization and ${ }^{1} \mathrm{H}-{ }^{31} \mathrm{P}$ cross polarization. ${ }^{31} \mathrm{P}$ direct polarization (DP) and cross polarization (CP) MAS spectra of the two samples are shown in Fig. S6. The phosphate lines of HAP (shown in blue) are slightly narrower than that of HAP.qOPN (shown in red) in both experiments, indicating a larger dispersion of the phosphate chemical shifts in the mineral prepared with the protein. As was shown before for HAP.ON29 and HAP.umOC, each of these phosphate lines, in fact, comprises several phosphate species, from the bulk of the crystalline material and from disordered mineral layers that cover the apatite crystals. This is further corroborated using $2 \mathrm{D}{ }^{1} \mathrm{H}-{ }^{31} \mathrm{P}$ HETCOR measurements which separate out phosphates based on protons in their vicinity. ${ }^{31} \mathrm{P}$ chemical shift anisotropy of $14.8( \pm 0.2) \mathrm{kHz}$ and asymmetry of $1.0( \pm 0.1)$ were measured for both materials from analysis of the sideband intensities in ${ }^{31} \mathrm{P} C P$ spectra recorded at slow spinning rates using the DMFIT program ${ }^{57}$ suggesting that the immediate environment of the $\mathrm{PO}_{4}{ }^{3-}$ ions is not affected by the preparation with qOPN.

To examine the individual magnetization transfers from different protons to phosphate species in HAP and HAP.qOPN, 2D ${ }^{1} \mathrm{H}-{ }^{31} \mathrm{P}$ HETCOR experiments, utilizing ${ }^{1} \mathrm{H}-{ }^{1} \mathrm{H}$ decoupling during ${ }^{1} \mathrm{H}$ evolution in $\mathrm{t}_{1}$, were performed. The use of PMLG decoupling with sample spinning at a rate of $10 \mathrm{kHz}$ is sufficient to average out ${ }^{1} \mathrm{H}-{ }^{1} \mathrm{H}$ dipolar couplings between ${ }^{1} \mathrm{H}$-containing mineral ions $\left(\mathrm{OH}^{-}\right.$and $\left.\mathrm{HPO}_{4}{ }^{2-}\right)$ and mobile water molecules but not to remove the couplings between the protons on qOPN and highly immobile water, therefore signals from protein protons near phosphate groups are not visible in the spectra. Two cross peaks are observed in the spectra of the 


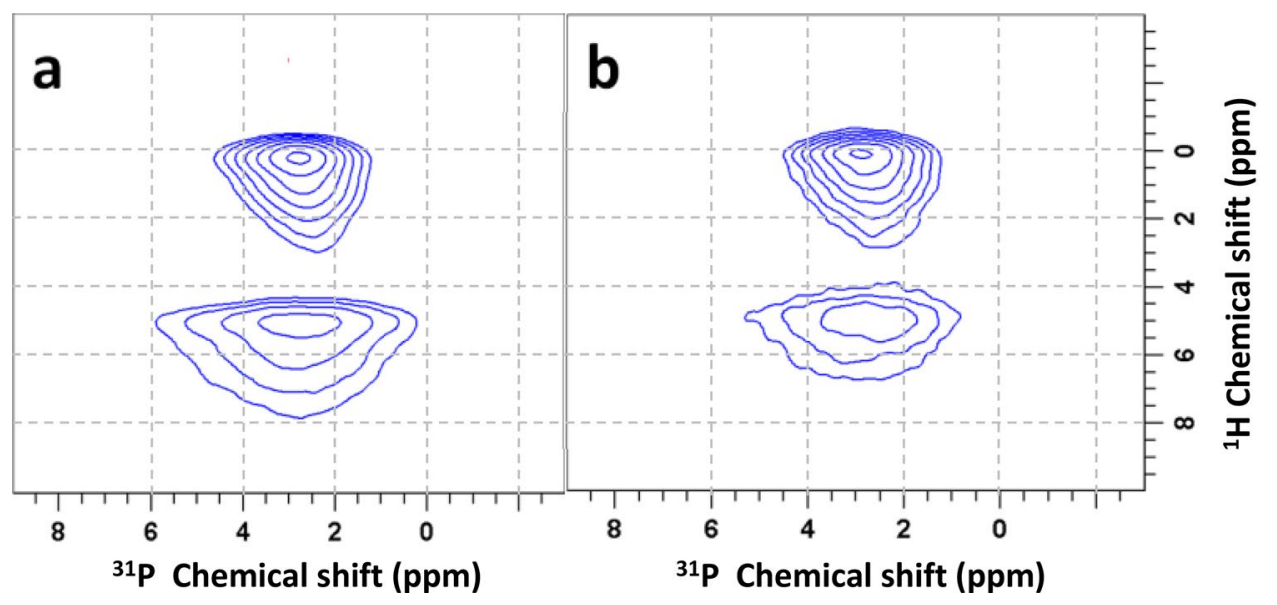

Figure 3. $2 \mathrm{D}{ }^{1} \mathrm{H}-{ }^{31} \mathrm{P}$ HETCOR spectra of HAP (a) and HAP.qOPN (b) recorded using the PMLG pulse scheme in $\mathrm{t}_{1}$ for ${ }^{1} \mathrm{H}$ homonuclear decoupling and a $\mathrm{CP}$ contact time of $0.8 \mathrm{~ms}$.

two material, shown in Fig. 3. A peak connecting phosphates with a ${ }^{1} \mathrm{H}$ resonance of $\mathrm{OH}^{-}$at 0.2 ppm representing mostly the bulk of apatite crystals and another peak connecting phosphates with ${ }^{1} \mathrm{H}$ resonances of $\mathrm{H}_{2} \mathrm{O}$ at $5.1 \mathrm{ppm}$ representing the hydrated layer of the mineral that covers each crystallite. The hydrated layer cross peak is broader along the ${ }^{31} \mathrm{P}$ axis indicating that the phosphates in this layer are disordered, as shown before for cortical bone $e^{10}$ and synthetic apatite preparations with ${ }^{27}$ and without ${ }^{58}$ bone proteins. The peaks are broad along the ${ }^{1} \mathrm{H}$ chemical shift axis due to heterogeneity in the sample which leads to chemical shift dispersion. For skyline projections along the ${ }^{1} \mathrm{H}$ and ${ }^{31} \mathrm{P}$ chemical shift axes in these $2 \mathrm{D}$ spectra see Fig. S7.

Interestingly, the NMR properties of the phosphates in this layer are sensitive to the protein used in the mineral synthesis. Here, for example, the disordered phosphate peak in HAP.qOPN is narrower than in HAP, indicating that the protein acts to decrease the degree of disorder in the surface layer, as was observed for umOC ${ }^{26}$. The reverse effect was observed for ON29, whereby the peptide induced greater disorder in this layer ${ }^{27}$. The surface layer cross peak in HAP.qOPN is also less intense, however, since quantitative intensities in CP experiments are generally challenging, it can be suggested that the relative amount of amorphous mineral layer is smaller in the presence of the protein, under the assumption of similar CP dynamics in two very similar preparations.

The cross peaks in the HETCOR spectra of the two materials comprise more than one phosphate species as evidenced from their asymmetric shape in a projection onto the ${ }^{31} \mathrm{P}$ axis. One-dimensional ${ }^{31} \mathrm{P}$ projections of the cross-peaks were, therefore, taken by slicing the HETCOR spectra in Fig. 3 horizontally at $0.2 \mathrm{ppm}$ and at $5.1 \mathrm{ppm}$. The resultant four projections were deconvolved using a two-line analysis in the DMFIT program. Example fittings for the $\mathrm{OH}^{-}$projections are shown in Fig. S8 for the two materials. The four phosphate species obtained for HAP.qOPN by fitting the $\mathrm{H}_{2} \mathrm{O}$ and $\mathrm{OH}^{-}$projections are shown in Fig. S9. Similarly, four phosphates are derived from analysis of the peaks in the 2D HETCOR spectrum of HAP. Summary of the spectral properties discerned for the phosphates in each material is given in Table 2. Note that the percentage of the total signal for each species in this table is instantaneous and a more adequate representation of the relative intensity of each phosphate in each sample is provided by analysis of their dynamic behavior as a function of the CP contact time (see Table 3).

This is further substantiated by examining the intensities of the cross peaks in a series of $2 \mathrm{D}{ }^{1} \mathrm{H}-{ }^{31} \mathrm{P}$ HETCOR measurements recorded at variable CP contact times. The intensity of each of the phosphate species, in the two cross peaks, builds up at a different rate. Therefore, by analyzing the set of projections obtained through slicing, as before, along the $\mathrm{H}_{2} \mathrm{O}$ and $\mathrm{OH}^{-}$resonances, the temporal intensity change per species is extracted (Fig. 4), for HAP-qOPN (blue symbols) and for HAP (red symbols). These experimental build-up curves are fitted to a theoretical CP buildup model (solid lines) using a home-written MATLAB minimization program.

$$
I(t)=I_{0}\left(1-\frac{T_{c p}}{T_{1 \rho}}\right)^{-1} \cdot\left(e^{\frac{-t}{T_{1 \rho}}}-e^{\frac{-t}{T_{c p}}}\right)
$$

The kinetic parameters of the fitted model are summarized in Table 3. Equation 1 is used to fit the graphs with the parameters, $I_{0}$ - the total magnetization of the phosphate species, $T_{c p}$-the effective magnetization buildup time (magnetization buildup occurs through ${ }^{1} \mathrm{H}-{ }^{31} \mathrm{P}$ dipolar couplings) and $T_{1 \rho}$ - the rotating-frame relaxation time which is usually taken as ${ }^{1} \mathrm{H} T_{1 \rho}$ time since the proton relaxation process is faster and is hence the governing mechanism. This model assumes negligible spin diffusion between proton spins and that $T_{c p}$ is shorter than $T_{1 \rho}$ ${ }^{59}$. When $T_{1 \rho} \gg T_{c p}$, the equation becomes simplified and independent of $T_{1 \rho}$. This occurs for several phosphate species where an asterisk is written in Table 3 instead of a value for $T_{1 \rho}$, indicating that the curve depends only on $I_{0}$ and $T_{c p}$. The total integrated intensity of the phosphate signal in HAP and HAP.qOPN is normalized to 1 .

The normalized $I_{0}$ values give a crude assessment of the relative amount of phosphate species (excitable by cross polarization) in each sample. For comparison between samples, similar CP dynamics is not required here, however, since for some species a maximum intensity was not measured, the reliability in determination of $I_{0}$ 


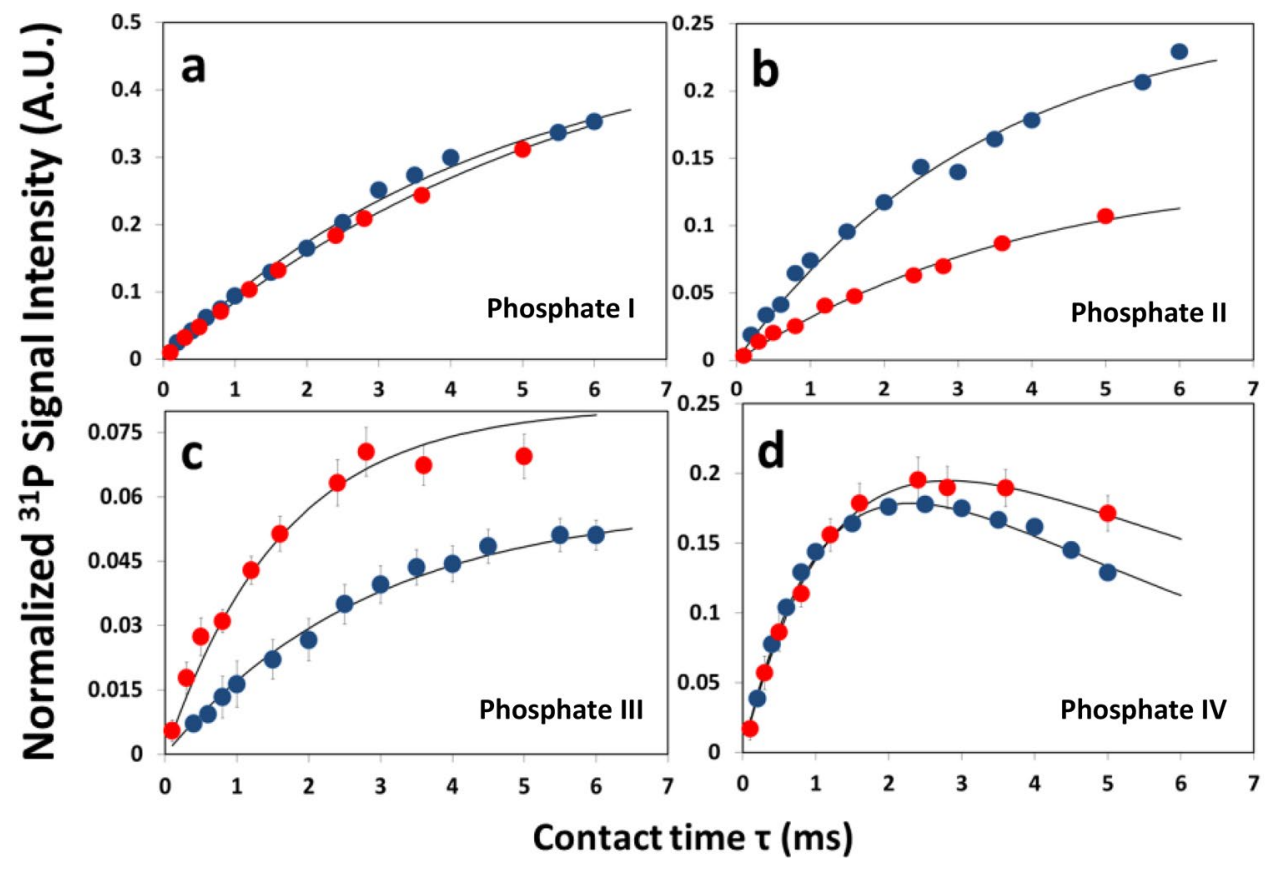

Figure 4. ${ }^{31} \mathrm{P}$ signal intensity buildup measured by varying the contact time in ${ }^{1} \mathrm{H}-{ }^{31} \mathrm{P}$ HETCOR measurements of HAP (red) and HAP.qOPN (blue). Graphs a and b show hydroxyl transfer to crystalline and partially disordered phosphates, respectively. Graphs $\mathrm{c}$ and $\mathrm{d}$ show water transfer to partially ordered and to disordered phosphates, respectively. In graphs (a) and (b) and partially in (d), calculated errors are within the size of symbols. HAP data shown were also reported before.

\begin{tabular}{|l|l|l|l|}
\hline Sample & $\boldsymbol{\delta}(\mathbf{p p m})$ & Line width (ppm) & \% of whole signal \\
\hline $\mathbf{H}_{2} \mathbf{O}$ & 2.6 & 3.0 & 27 \\
\hline \multirow{2}{*}{ HAP } & 3.3 & 5.6 & 73 \\
\hline \multirow{2}{*}{ HAP·qOPN } & 2.6 & 2.7 & 28 \\
\cline { 2 - 4 } & 3.4 & 5.4 & 72 \\
\hline OH & 2.9 & 1.7 & 75 \\
\hline \multirow{2}{*}{ HAP } & 3.3 & 3.5 & 25 \\
\hline \multirow{2}{*}{ HAP·qOPN } & 2.9 & 1.7 & 61 \\
\cline { 2 - 4 } & 3.3 & 3.3 & 39 \\
\hline
\end{tabular}

Table 2. Deconvolution results of one-dimensional ${ }^{31} \mathrm{P}$ projections of HAP and HAP.qOPN. Uncertainties in $\delta$ and line width are below $\pm 0.05 \mathrm{ppm}$ and errors in relative signal intensities are $<5 \%$.

\begin{tabular}{|l|l|l|l|l|l|l|l|}
\hline HAP & $\mathbf{T}_{\mathbf{c p}}(\mathbf{m s})$ & $\mathbf{T}_{\mathbf{l}}(\mathbf{m s})$ & $\mathbf{I}_{\mathbf{o}}$ & HAP.qOPN & $\mathbf{T}_{\mathbf{c p}}(\mathbf{m s})$ & $\mathbf{T}_{\mathbf{1 p}}(\mathbf{m s})$ & $\mathbf{I}_{\mathbf{o}}$ \\
\hline I & $5.7 \pm(0.1)$ & $*$ & $0.53 \pm(0.08)$ & I & $5.5 \pm(0.1)$ & $*$ & $0.53 \pm(0.07)$ \\
\hline II & $3.2 \pm(0.3)$ & $*$ & $0.16 \pm(0.02)$ & II & $3.4 \pm(0.2)$ & $*$ & $0.25 \pm(0.04)$ \\
\hline III & $1.6 \pm(0.3)$ & $*$ & $0.12 \pm(0.02)$ & III & $2.9 \pm(0.4)$ & $*$ & $0.06 \pm(0.02)$ \\
\hline IV & $1.3 \pm(0.2)$ & $7.9 \pm(0.3)$ & $0.19 \pm(0.05)$ & IV & $1.2 \pm(0.3)$ & $5.3 \pm(0.2)$ & $0.16 \pm(0.03)$ \\
\hline
\end{tabular}

Table 3. Kinetic parameters of the ${ }^{31} \mathrm{P}$ magnetization $\mathrm{CP}$ buildup for HAP and HAP.qOPN. ${ }^{\star}$ The case where $\mathrm{T}_{1 \rho}{ }^{-1}<<\mathrm{T}_{\mathrm{cp}}{ }^{-1}$ and its contribution is therefore neglected.

is somewhat limited. Therefore, the comparison between intensities of different phosphates and relative sizes of phases (bulk, intermediate and surface) is not stringently quantitative. Under these restrictions, it is evident that the relative proportion of bulk:intermediate:surface in HAP.qOPN is 53:31:16 and that in HAP it is 53:28:19. 


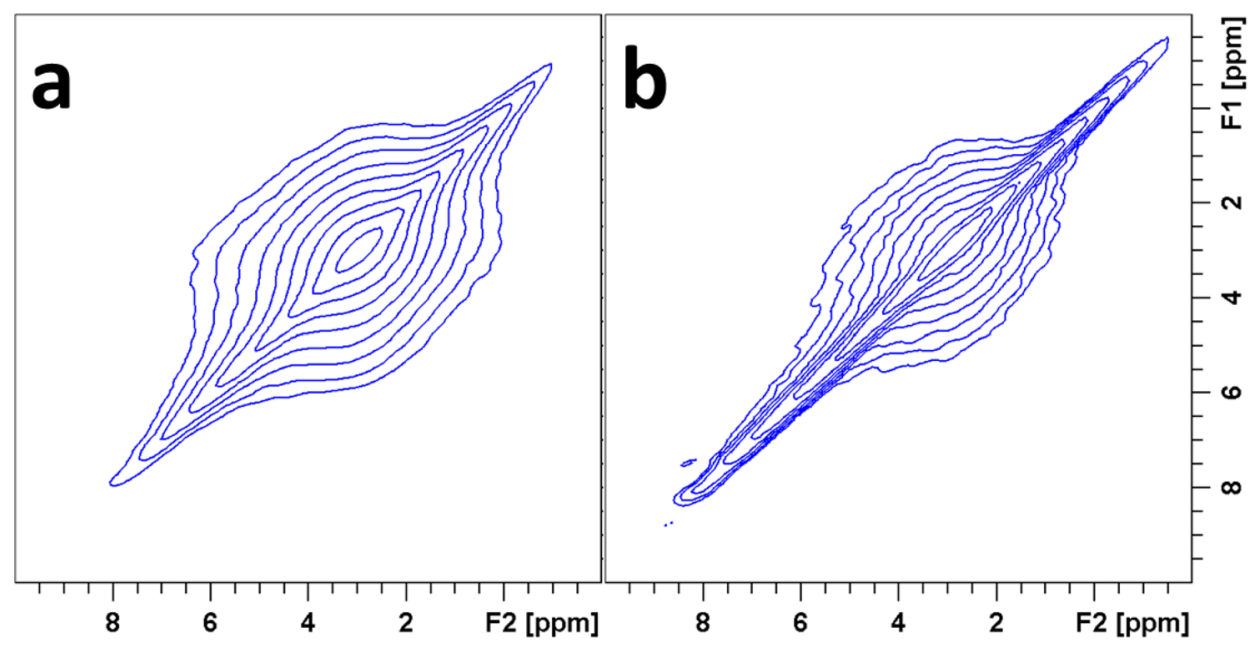

Figure 5. ${ }^{31} \mathrm{P} 2 \mathrm{D}$ DARR spectra of HAP (a) and HAP.qOPN (b) recorded using a contact time of 2 ms, a proton mixing time of $500 \mathrm{~ms}, 32$ scans, and a recycle delay of $2 \mathrm{~s}$.

The relative intensity of surface layer phosphates, excited via water protons (species IV), is slightly lower with the protein than without it. A similar phenomenon was also observed for HAP·umOC and for HAP.ON2926,27.

$2 D^{31} \mathrm{P}$ dipolar-assisted rotational resonance (DARR) experiment. Further evidence for protein effect on cross phase magnetization transfer between phosphates in the mineral is inferred from $2 \mathrm{D}{ }^{31} \mathrm{P}$ DARR experiment (Fig. 5). The phosphate diagonal peak is broader in HAP than in the mineral prepared with qOPN showing offdiagonal ridges from cross-species magnetization exchange extending to phosphate species at chemical shifts as high as $5.0 \mathrm{ppm}$. For the HAP.qOPN spectrum, the magnetization exchange is narrower involving mainly the disordered mineral at $3.2 \mathrm{ppm}$ and up to $\sim 3.5 \mathrm{ppm}$.

NMR results of qOPN interactions with mineral phases. $1 D$ CHHP relayed magnetization transfer experiments. The identification of disordered layers covering apatite crystallites also lead us to investigate qOPN location within these layers in HAP.qOPN. NMR measurements designed to detect phosphates at various distances from the carbon atoms in the protein, using the CHHP relayed transfer experiment ${ }^{60}$ (Fig. S10), were first employed. In the experiment, the ${ }^{31} \mathrm{P}$ magnetizations of phosphates in the mineral phases are excited by $\mathrm{qOPN}{ }^{13} \mathrm{C}$ magnetizations, through various mediating hydrogens from the protein and from the minerals. During a designated proton mixing time $\left(\tau_{m}\right)$ in the CHHP experiment, the protons are allowed to exchange magnetization between themselves, thereby enhancing transfer between distant ${ }^{13} \mathrm{C}-{ }^{31} \mathrm{P}$ pairs of nuclei via the stronger ${ }^{1} \mathrm{H}-{ }^{1} \mathrm{H}$ couplings. The protons, hence, facilitate indirect magnetization transfer pathways from ${ }^{13} \mathrm{C}$ nuclei to more distant ${ }^{31} \mathrm{P}$ nuclei and bypass the truncation of such pathways by closer ${ }^{31} \mathrm{P}$ nuclei in direct transfer experiments such as TEDOR and double CP shown later.

The ${ }^{31} \mathrm{P}$ CHHP spectrum of HAP.qOPN (Fig. 6a), obtained using a $\tau_{m}$ of $120 \mathrm{~ms}$, shows a phosphate peak that comprises both disordered and crystalline phosphate species. The ${ }^{31} \mathrm{P}$ spectra obtained at increasing $\tau_{m}$ are displayed in Fig. 6b, in a slanted view for clarity. At short mixing times, the spectra are broad comprising only disordered phosphates that obtain magnetization from carbons first. At longer mixing times the spectra are getting narrower and stronger and the phosphate peak shifts slightly to the left, indicating that crystalline phosphates are getting increasingly more magnetized.

A plot of the phosphate magnetization intensity as a function of the mixing time, $\tau_{m}$, shows that the disordered phase ${ }^{31} \mathrm{P}$ magnetization (Fig. $7 \mathrm{a}$ ) reaches its maximal intensity after $30 \mathrm{~ms}$, whereas crystalline phase ${ }^{31} \mathrm{P}$ magnetization (Fig. $7 \mathrm{~b}$ ) reaches a plateau in its value at $\sim 100 \mathrm{~ms}$. Phosphates in the disordered mineral layers interact strongly with the protein carbons and obtain more than half of their maximal magnetization via a single mediating proton before any proton exchange processes were turned on. Apatite phosphates require magnetization to be relayed from protons on the protein to protons that are near the crystal surface, in a process with a longer characteristic time. A model to describe the transfer from ${ }^{13} \mathrm{C}$ spins to the various ${ }^{31} \mathrm{P}$ spins through the ${ }^{1} \mathrm{H}$ "spin bath" is being constructed, but the qualitative comparison clearly indicates that the protein resides in closest proximity to the disordered phase phosphates and is farther removed from faces of the crystal, therefore, it is able to transfer magnetization to the core apatite phosphates only through protons that populate the intermediate layers closer to it and only at longer mixing times.

$2 D^{31} P_{-}{ }^{13} \mathrm{C}$ double $C P$ and ${ }^{13} \mathrm{C}_{-}{ }^{31} \mathrm{P} z$ TEDOR experiments. $\quad 2 \mathrm{D}^{31} \mathrm{P}-{ }^{13} \mathrm{C}$ and ${ }^{13} \mathrm{C}-{ }^{31} \mathrm{P}$ correlation measurements of HAP.qOPN were also carried out to investigate direct transfer of magnetization from phosphates in the mineral to spatially proximate carbon atoms in qOPN molecules. The $2 \mathrm{D}^{31} \mathrm{P}-{ }^{13} \mathrm{C} \mathrm{DCP}$ spectrum shown in Fig. $8 \mathrm{a}$ exhibits cross peaks between crystalline apatite phosphate resonance at $2.8 \mathrm{ppm}$ (along the vertical axis) and carbon resonances at $51.4 \mathrm{ppm}$ and at $38.3 \mathrm{ppm}$ (along the horizontal axis), that, as a pair, can be assigned to Asn Ca and 

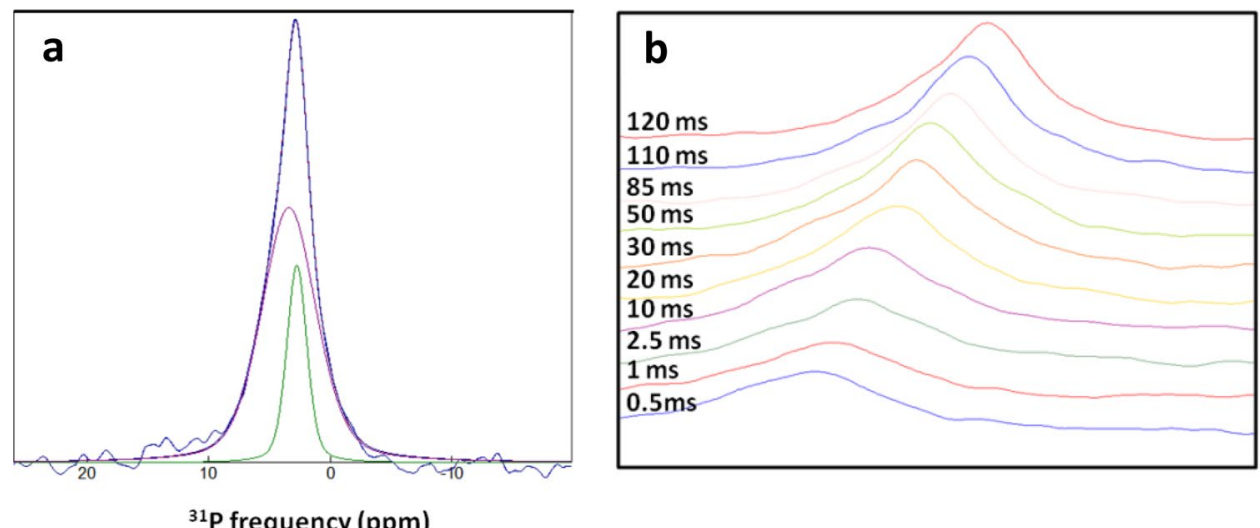

${ }^{31} \mathrm{P}$ frequency $(\mathrm{ppm})$

Figure 6. (a) 1D CHHP spectrum of HAP.qOPN (blue) recorded using HH mixing time of $120 \mathrm{~ms}$. The line is comprised of two phosphate species, apatite phosphate (green line) and disordered phosphate (magenta line) obtained by deconvolution. (b) The buildup of phosphate magnetization in the 1D CHHP spectrum, given on the left, as a function of the $\mathrm{HH}$ mixing time, showing initial transfer to disordered $\mathrm{PO}_{4}{ }^{3-}$ and a gradual increase of the crystalline $\mathrm{PO}_{4}{ }^{3-}$ at longer mixing time.
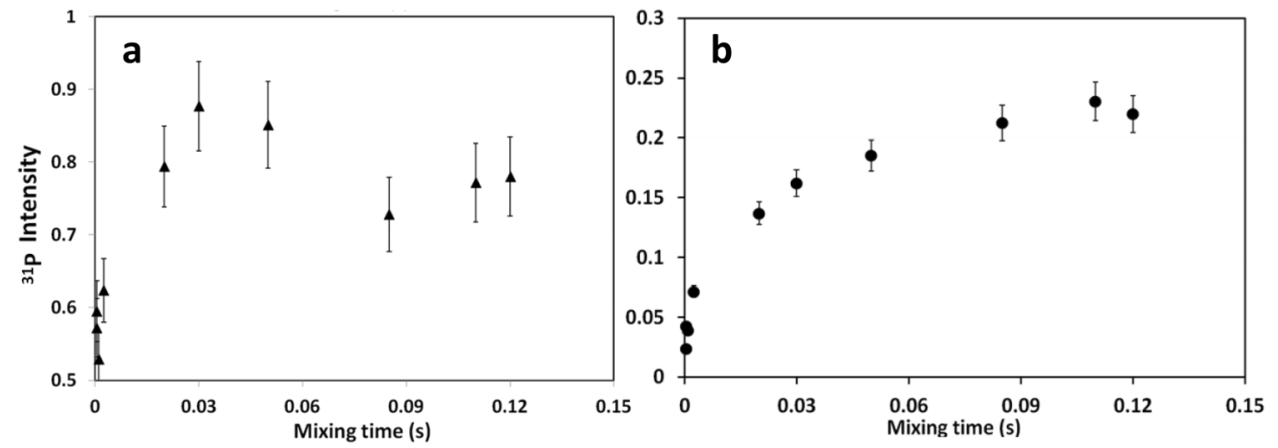

Figure 7. Buildup of ${ }^{31} \mathrm{P}$ magnetization in $1 \mathrm{D}$ CHHP spectrum of HAP.qOPN as a function of the $\mathrm{HH}$ mixing time. (a) The disordered phosphate line buildup and (b) The apatite phosphate line buildup.
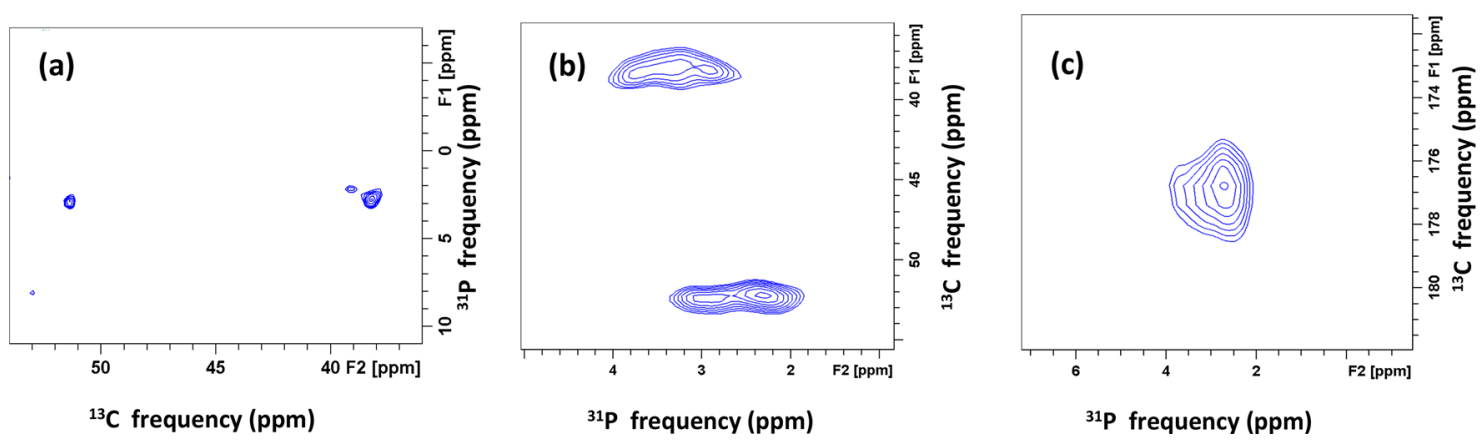

Figure 8. (a) $2 \mathrm{D}^{31} \mathrm{P}-{ }^{13} \mathrm{C}$ double-CP spectrum of HAP.qOPN with contact time of $5 \mathrm{~ms}$ between ${ }^{1} \mathrm{H}$ and ${ }^{31} \mathrm{P}$, and $16 \mathrm{~ms}$ contact time between ${ }^{31} \mathrm{P}$ and ${ }^{13} \mathrm{C}$ showing only two cross peaks between apatite phosphate ions at $2.8 \mathrm{ppm}$ and qOPN carbons. No cross peaks with the disordered phosphates are observed. (b) The aliphatic region and (c) the carbonyl region in the $2 \mathrm{D}$ rotor-synchronized ${ }^{13} \mathrm{C}-{ }^{31} \mathrm{P} z$-filtered TEDOR spectrum of HAP.qOPN.

Asn $\mathrm{C} \beta$, respectively. This measurement was carried using a ${ }^{31} \mathrm{P}-{ }^{13} \mathrm{C} \mathrm{CP}$ contact time of $16 \mathrm{~ms}$ since shorter times did not produce cross peaks in the $2 \mathrm{D}$ spectra. The measurement suggests that only a single contact is observed between the apatite crystals and carbons in qOPN (entire spectrum is shown in Fig. S11).

The $2 \mathrm{D}^{13} \mathrm{C}-{ }^{31} \mathrm{P}$ z-filtered TEDOR ${ }^{61}$ spectra for the HAP.qOPN sample are shown in Fig. $8 \mathrm{~b}$ (aliphatic region) and Fig. 8c (carbonyl region). Full z-filtered spectra are shown in Figs. S12 and S13. The cross peaks in the aliphatic region appearing at $\sim 52 \mathrm{ppm}$ and at $\sim 38 \mathrm{ppm}$, correlate to the apatite phosphate resonance at $2.9 \mathrm{ppm}$. 
These correlations connect the same carbons to the apatitic phase as the cross peaks in ${ }^{31} \mathrm{P}-{ }^{13} \mathrm{C} \mathrm{DCP}$ spectrum in Fig. 8a. The results, using two dipolar recoupling NMR techniques, confirm that only two types of aliphatic carbons in the whole protein are proximate to crystal surface of apatite and these are best associated with Asn $\mathrm{C} \alpha$ and Asn $\mathrm{C} \beta$. Moreover, the carbonyl region spectrum (Fig. 8c) shows a strong cross peak at $176.8 \mathrm{ppm}$ in ${ }^{13} \mathrm{C}$ frequency with the apatite phosphate as well. This peak is not uniquely assigned, as it fits the frequency of carbonyls from various amino acids. However, it can also represent Asn $\mathrm{C} \gamma$, thereby, providing a more suitable view of the entire asparagine sidechain as being aligned very close to the crystal surface. Additional smaller cross peaks of carbonyl carbon (at $\sim 177 \mathrm{ppm}$ ) with non-apatite phosphates are seen in Fig. $8 \mathrm{c}$.

Discussion. Influence of $q O P N$ and other non-collagenous proteins on apatite crystallites. HRTEM data show that the mineral crystallites formed in HAP.qOPN, like in HAP.umOC ${ }^{26}$ and HAP.ON50 ${ }^{29}$, have morphology and dimensions similar to that found in apatite platelets in bone, contrarily to HAP.ON2927,28, where needle-shaped crystallites are formed. The powder XRD data further corroborate the mild effect of qOPN on apatite crystallite properties compared to either ON29 or umOC. Though non-phosphorylated qOPN was reported to have no effect on apatite mineralization onset and crystal growth ${ }^{32}$, it is still interesting that it exhibits no marked changes to apatite crystallite characteristics, given its high content (24\%) of Glu/Asp residues. The protein, however, has a marked effect on the disordered phases formed together with the apatite crystallites, observed via ICP and NMR measurements.

The dense crystallite aggregates observed in the scanning electron micrographs of HAP.qOPN relative to HAP resemble the ones recorded on HAP.ON29. They may be caused by strong adsorption forces of the biomolecules which can adhere to more than one crystallite thereby inducing aggregation by agglutination ${ }^{27,28}$. This also manifested in the lower SSA measured for HAP.qOPN than for HAP or for HAP.ON29. Moreover, the reported interactions between OPN molecules to form homodimers in addition to weaker dimer-monomer binding ${ }^{62}$ support the agglutination property and reduced SSA of qOPN-HAP as compared to OC and ON. Previous TGA measurements of HAP.ON29 showed that the peptide constitutes 4.8 weight\% (1.6 mol\%) of the material. Similarly, TGA of HAP.umOC showed that umOC constitutes 8.0 weight $\%$ of the material $(1.4 \mathrm{~mol} \%)^{26,28}$. Molar content of qOPN in the protein-mineral composite formed is much lower than ON29 or umOC. Interestingly, its pyrolysis is centered at a temperature $20^{\circ} \mathrm{C}$ higher than umOC in HAP.umOC and ON29 in HAP.ON29, which asserts the stronger binding to the outer surfaces of apatite crystallites inferred from the SEM and specific surface area measurements.

The larger $\mathrm{Ca} / \mathrm{P}$ ratio in the entire HAP.qOPN sample comprising the minerals and the protein, concurrently with hydroxyapatite being the only crystalline phase formed, indicates a depletion of phosphates from the non-crystalline phases detected by NMR. Similar Ca/P ratios were obtained in HAP.ON29 (1.82) and in an osteoporotic rib bone of a rabbit ${ }^{63}$. In HAP.umOC, Ca/P ratios were lower than HAP (1.56) indicating deficiency of $\mathrm{Ca}^{2+}$ ions from the disordered mineral phases as a result of the activity of umOC. Overall, variation of the ion composition in the amorphous mineral layers coating the apatite crystallites is one of the hallmarks of NCPs activity.

Identification of four different phosphate species. The $1 \mathrm{D}{ }^{1} \mathrm{H}-{ }^{31} \mathrm{P} \mathrm{CP}$ experiments suggests a well-ordered phosphates from the bulk of the apatite crystals excited by $\mathrm{OH}^{-}$protons, denoted "species I", (peak at 2.9 ppm FWHM $1.7 \mathrm{ppm}$ ) and disordered phosphates from the disordered layer that covers apatite crystallites excited by water protons, denoted " species IV", (peak at 3.3-3.4 ppm FWHM 5.4-5.6) are commonly known and were identified by NMR before ${ }^{9,10,58}$. In addition, partially disordered phosphates excited by $\mathrm{OH}^{-}$protons, denoted "species II", (peak at 3.3 ppm FWHM 3.3-3.5 ppm) and partially ordered phosphates excited by water protons, denoted "species III", (peak at 2.6 ppm FWHM 2.7-3.0 ppm) are also detected. The latter two new phosphate species, recognized recently ${ }^{26,27}$, define an intermediate mineral phase which resides spatially between the bulk apatite crystal and outer disordered phase. This phase contains $\mathrm{PO}_{4}{ }^{3-}$ and $\mathrm{HPO}_{4}{ }^{2-}$ ions characterized by transitional order (or disorder) compared to the crystalline and amorphous phases, as can be noticed from their intermediate linewidths.

It is evident from the intensities of the intermediate phase species that they constitute qualitatively, a significant proportion of the phosphates excitable by cross polarization in the samples. Yet, rigorous quantification of the absolute content of each phosphate species requires further scrutiny. The appearance of the phosphate at $2.6 \mathrm{ppm}$ associated with protonated phosphate $\left(\mathrm{HPO}_{4}{ }^{2-}\right)$ is interesting. It was observed before in HAP.umOC but not in HAP.ON2926,27. The proteins, qOPN and umOC, have similar isoelectric point of 4.2-4.4 and may therefore have a similar effect on the $\mathrm{PO}_{4}{ }^{3-} \rightleftharpoons \mathrm{HPO}_{4}{ }^{2-}$ equilibrium, whereas the peptide with its more acidic $\mathrm{pI}$ of 3.2, maintains trivalent state of the ions.

The inter-phase phosphates (species III) have similar linewidth and proportionality out of the total disordered phosphate phase in HAP.qOPN like in HAP. The other inter-phase phosphates (species II), however, take up a larger fraction of the ordered phosphates with the protein as compared to HAP alone. The bulk phosphates (species I) linewidth is the same with qOPN and ON29 as in HAP and is slightly broader than in HAP.umOC, affirming that umOC is the only NCP that improves the order of these ions in the apatite crystal. The disordered phosphates in the surface layer (species IV) are marginally narrower with qOPN than in HAP alone or in HAP.umOC but are similar to preparation with ON29.

The interphase's disordered species (species II) in HAP.qOPN is slightly broader than in HAP.umOC and HAP.ON29, suggesting that phosphates closer to the outer surfaces of apatite crystals are strongly perturbed by the $\mathrm{qOPN}^{26,27}$. On the other hand, the interphase's ordered species (species III) in HAP.qOPN is narrower than other preparations indicating that qOPN induces an increase of ion ordering near the outer surface layer. Note 
that in HAP.ON29, this species appears at $2.8 \mathrm{ppm}$, however, it is not an apatitic phosphate, but rather a mix of partially ordered $\mathrm{PO}_{4}{ }^{3-}$ and $\mathrm{HPO}_{4}{ }^{2-}$ ion resonances that on average give a maximum peak at $2.8 \mathrm{ppm}$.

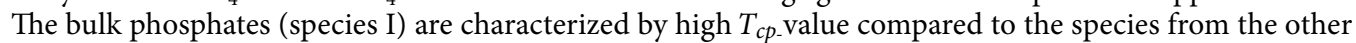
phases. This indicates that the rate of magnetization transfer to phosphorous atoms in the apatite crystal are the lowest, in accordance with the relatively long internuclear distances between $\mathrm{OH}^{-}$protons and phosphate ${ }^{31} \mathrm{P}$ nuclei in the lattice. The surface layer phosphates (species IV) show the lowest $T_{c p}$ values, $1.2 \mathrm{~ms}$ in HAP.qOPN and $1.3 \mathrm{~ms}$ in HAP indicating that they experience the strongest cumulative interaction with several protons. The interphase phosphates (species II and III) in HAP.qOPN, have similar $T_{c p}$, which is intermediate between the bulk and surface. In HAP, this parameter is quite different for the two species and suggests that qOPN's presence in this layer may serve to balance the effective coupling experienced by phosphates close to faces of the crystal and close to the outer surface layer. This is unique to qOPN, as neither umOC ${ }^{26}$ nor ON2927 exhibit a similar effect on the interphase species. The $T_{c p}$ value of surface phosphates (species IV) in HAP.qOPN (1.2 ms) is close to value measured for fresh bone $(1.1 \mathrm{~ms})^{10}$.

The only species with measurable $T_{1 \rho}$ time is the surface layer one (species IV). The smaller the value of $T_{1 \rho}$ measured, the more effective are the motions that induce faster relaxation in the proton nuclei. For HAP.qOPN, this value is significantly smaller than for HAP, indicating that motions at the microsecond to millisecond time scale occur in the presence of the protein and these are efficiently promoting the faster relaxation detected. Whether this motions can be associated with hydrogen atoms in the protein, water molecules or protons on various ions requires further investigation, however, in the case of qOPN they produce lower $T_{1 \rho}$ compared than measured with umOC ${ }^{26}$ and higher compared to values measured with ON2927.

It is observed that the negatively charged protein, located in the disordered phases covering the apatite crystallites, decreases the content of phosphate species $\left(\mathrm{PO}_{4}{ }^{3-}\right.$ and $\left.\mathrm{HPO}_{4}{ }^{2-}\right)$ in the disordered layer as observed by the ICP results as well. The $\mathrm{I}_{0}$ values are the relative populations of phosphate groups in different phases which allow us to estimate the $\mathrm{Ca} / \mathrm{P}$ ratio in the surface and interphase jointly based on the ICP results and the stoichiometry of $\mathrm{Ca} / \mathrm{P}$ in the apatite crystals. $\mathrm{Ca} / \mathrm{P}$ ratio in the disordered phases was calculated for HAP.qOPN in the following way: $\mathrm{Ca} / \mathrm{P}_{\text {(surface+interface) }}{ }^{\star} 0.47+1.67^{\star} 0.53=1.78, \mathrm{Ca} / \mathrm{P}_{\text {(surface+interface) }}=1.90$, taking the total relative intensity of the surface and interphase species from Table 3. The $\mathrm{Ca} / \mathrm{P}_{\text {(surface+interface) }}$ value obtained for HAP is 1.65 . The ion balance in the disordered phases, as can be seen, is influenced considerably by the negatively charged qOPN whereas the thickness of the interphase is only marginally affected. The phosphate depletion from the disordered phases with qOPN is, however, less extensive than with ON2927. Overall, it is evident that the NCPs affect the interphase differently, showing the regulatory capability over the minerals formed.

Interactions between different phosphate phases. The DARR measurement allows us to monitor slower spin diffusion processes and to observe magnetization transfer between phosphates that are farther apart. Here, it serves as a fingerprint for the extent of coupling between the crystalline phase (resonating at 2.8-2.9 ppm) and the amorphous phases, represented by phosphate peaks which are seen to extend all the way to $5.0 \mathrm{ppm}$. The de-shielded ${ }^{31} \mathrm{P}$ nuclei in these amorphous phosphate species were typically invisible or buried under larger species in the standard ${ }^{31} \mathrm{P}$ measurement. They represent minor populations of the ions that, in the presence of the protein molecules, shift downfield. In HAP, there is efficient transfer from the core crystallites to surface phosphates resonating at $5.0 \mathrm{ppm}$, whereas, in HAP.qOPN the transfer is limited between crystalline phosphates and phosphates at $3.5 \mathrm{ppm}$, characterized by a relatively narrow line width.

Confirmation of location of qOPN in interfacial disorder mineral phases. The CHHP measurement shows that the qOPN molecules are located in disordered mineral layers covering the apatite crystallites and they exert activity from this location. This also explains the stronger influence of the protein on the properties of the disordered hydrated layers than on apatite crystallites. qOPN is able to alter the composition of mineral ions in this layer, pushing more $\mathrm{Ca}^{2+}$ ions to accommodate the layer than phosphate ions. It affects also the dynamic properties of the water and phosphate ions in this layer as compared to the properties of these moieties in HAP, as inferred from the CP buildup experiments shown above.

In addition, the higher sensitivity in the TEDOR measurements reveals that Asn $C \beta$ carbon at $\sim 38 \mathrm{ppm}$ is correlated with two more phosphate species centered at $\sim 3.3 \mathrm{ppm}$ and at $\sim 3.8 \mathrm{ppm}$. In addition, the Asn Ca carbon is correlated to a phosphate species at $\sim 2.3 \mathrm{ppm}$ along the ${ }^{31} \mathrm{P}$ axis. The linewidths of these phosphates are evidently similar to the linewidth of the apatite line, suggesting that they are associated with highly ordered phosphate ions. Their chemical shifts match the shifts of phosphates P1 (3.8 ppm), P4 (3.3 ppm) and P2 (2.0 ppm) in crystalline octacalcium phosphate (OCP). Out of the six unique phosphates in the crystal lattice of OCP, these three are closer to the apatite layer ${ }^{64}$. It is quite compelling to observe the interaction of specific carbons in the Asn residue with crystallographically unique phosphates in OCP and in any mineral in general. This would be hard to observe in hydroxyapatite which has its three unique phosphates appearing at the same chemical shift ${ }^{65}$.

The scarcity of cross peaks between the protein and crystalline apatite phosphates is consistent with the CHHP results and asserts the presence of most of the protein away from the crystallite surface with only a single type of residue in direct interaction with it. At the same time, the absence of cross peaks between qOPN carbons and disordered phosphates is less obvious, since CHHP data indicated residence of the protein in the disordered layers. This can be explained by motional averaging of phosphates in these layers and/or protein sidechains that efficiently averages the direct magnetization transfer between disordered phosphates and qOPN carbons but is ineffective in case of the relayed transfer through the adjacent protons. The phosphates in the coat layers were shown above to experience motions. Other measurements, which will be reported elsewhere, indicate that the protein retains considerable amount of dynamics in the mineral-bound state as well. 


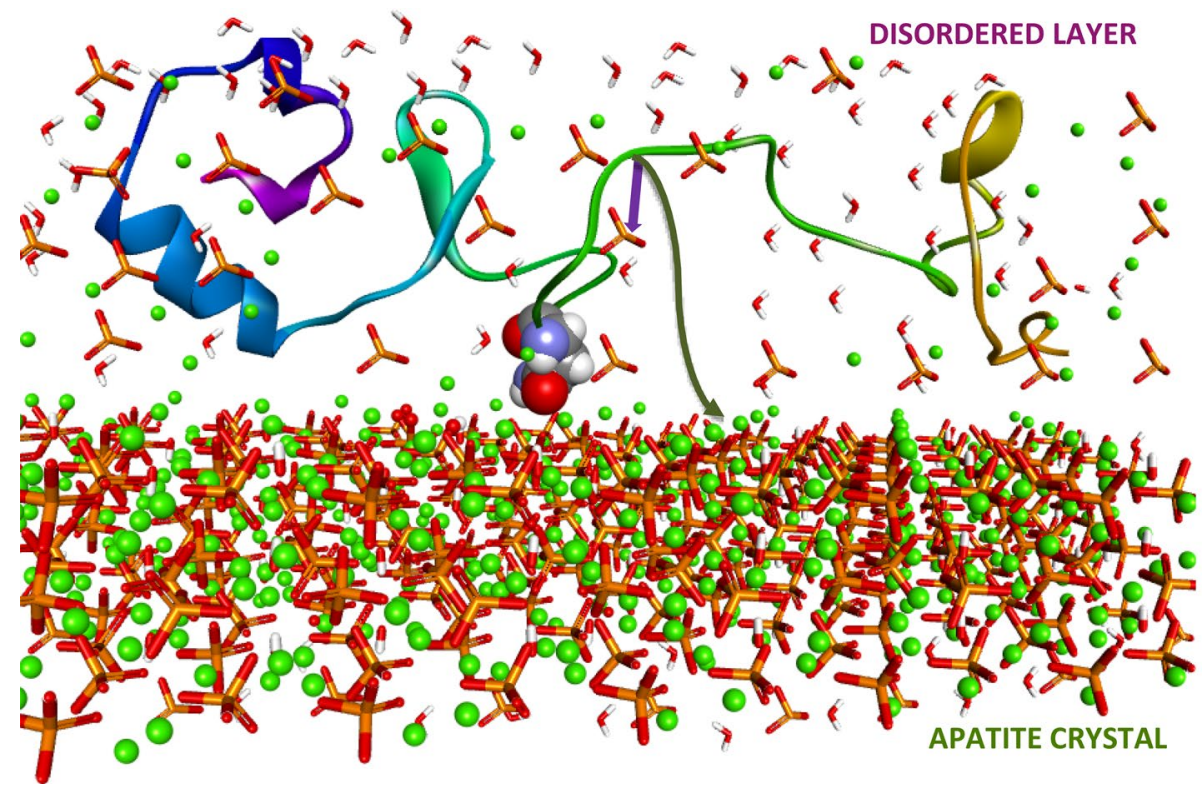

Figure 9. NMR-based model showing qOPN (structure predicted using the ROSETTA algorithm ${ }^{67}$ ) located in a disordered layer covering the apatite crystal and having Asn sidechain able to reach in and interact with the surface of the crystal. Purple and green arrows represent magnetization transfers first to disordered $\mathrm{PO}_{4}{ }^{3-}$ ions and later to apatite $\mathrm{PO}_{4}{ }^{3-}$ ions.

The common paradigm of the bio-inorganic interface, formed between OPN, as well as other non-collagenous proteins, with bone apatite and other important biominerals, assumes binding of the protein mineral to flat well-ordered faces of apatite crystals ${ }^{66}$. Other visualizations of the interaction using molecular dynamics simulations, interestingly, have shown OPN binds intermittently to surfaces of crystals while retaining some of its intrinsic dynamic behavior as an $\mathrm{IDP}^{36}$. However, none of the current models, accounts for the observation of non-vanishing disordered layers coating the exposed faces of the apatite crystallites.

Given the observed protein-mineral interactions in this work, predominantly through the disordered layers, the view of the direct atomic interface between protein molecules and mineral ions may need to be modified. A revised view of the mineral present at the bio-inorganic interface, shown in Fig. 9, which includes the persistent disordered phases of calcium encompassing phosphate ions with which the protein interacts predominantly. Residence in a disordered mineral phase may preserve some of the protein's solution motions, since the mineral ions themselves, are unconstrained by the crystal field in such layers, and thus may be experiencing motions.

Activity of functional proteins in such environment, crowded by inorganic ions, that is quite different from the typically considered cellular environment, crowded mostly with other biomacromolecules, is interesting and may require modification of the potentials and forcefields used to model their structure, dynamics and binding energy. Proteins with pronounced motional characteristics in solution such as intrinsically disordered proteins, especially ones with polyproline segments, might be able to retain some of their dynamics in the crowded regions such as disordered mineral phases. The view of OPN as a flexible electrolyte may still hold for protein molecules embedded in disordered mineral layers, however, the denser environment of ions needs to be accounted for in modeling these motions.

The involvement of at least a single residue sidechain in direct interaction with the crystal face of apatite and OCP indicates that for qOPN and perhaps for other NCPs, contact with the crystalline phase is maintained even if it is quite subtle. Binding to specific crystal faces (face recognition) through multiple contact points and control over crystal growth directions and morphology was not observed here for non-phosphorylated version of quail osteopontin, however, it may represent the functional mechanism of phosphorylated OPN and its fragments as well as other NCPs. The use of a high-resolution technique such as solid-state NMR exemplifies the importance of having an atomic view of the interaction interface experimentally to appreciate the complexity of mechanisms underlying the end-product biomaterials that are generated in organisms.

\section{Conclusions}

OPN is shown to have an impact on the mineralization of apatite at physiological temperature under controlled conditions. The mineral is precipitated with as much as a quarter mol\% of the protein. The core apatitic crystallites preserve their platelet-like morphology but tend to agglomerate in the presence of OPN, suggesting an agglutinating property for the protein. NMR measurements show that an appreciable disordered calcium phosphate mineral layer covers the apatite crystallites. From quantification of $\mathrm{Ca}$ and $\mathrm{P}$ in HAP.qOPN, it is clear that the surface layer is depleted of phosphate groups. Solid state NMR techniques allow further identification of various disordered phase ${ }^{68,69}$. A partially ordered mineral inter-phase layer between the ordered and disordered phases is observed in HAP·qOPN as was shown recently for other bone proteins. The magnetization transfer dynamics 
proves to be a sensitive tool to trace the influence of qOPN on the disordered mineral phases that form with the apatite crystallites and to elaborate on its distinct effects compared to other bone proteins. Finally, it is shown for the first time through the CHHP, $2 \mathrm{D}^{31} \mathrm{P}-{ }^{13} \mathrm{C}$ DCP and $2 \mathrm{D}{ }^{13} \mathrm{C}-{ }^{31} \mathrm{P}$ z-filtered TEDOR experiments that the protein resides in the disordered coating layers with one or few sidechains at most reaching the faces of the apatite crystallites and therefore exerts its regulating function on the crystals formed from a distance.

Understanding the binding and activity of qOPN as a key NCP in regulation of apatite homeostasis, gives leads to how properties of other mineralized materials are regulated. The formation of an interphase between a crystalline phase and a disordered layer (aka amorphous calcium phosphate) and the ability of NCPs to regulate the composition of disordered phases may be a common mechanism of mineral regulation and may have ramifications for the mechanical properties of bone mineral. The NMR analyses demonstrated in this work can help understand the pathological impact of lack or deficiency of key biomolecules such as osteopontin on mineralization processes.

\section{Experimental}

Materials. Di-ammonium hydrogen phosphate $\left(\mathrm{NH}_{4}\right)_{2} \mathrm{HPO}_{4} 99 \%$ and calcium nitrate tetrahydrate $\mathrm{Ca}\left(\mathrm{NO}_{3}\right)_{2} \cdot 4 \mathrm{H}_{2} \mathrm{O} 99 \%$ were purchased from Merck and Sigma Aldrich, respectively. Ammonium hydroxide $\mathrm{NH}_{4} \mathrm{OH}$ was purchased from BioLab Ltd.

Bioexpression of quail OPN was carried out similarly to procedure reported recently ${ }^{70}$. Coturnix japonica (or quail) OPN DNA sequence was cloned into a pET11d plasmid and was then transformed into a phage resistant E. coli strain BL21(DE3) via a heat-shock technique. Expression of the protein was induced at $\mathrm{OD}_{600}$ of approximately 0.8 by addition of $0.4 \mathrm{mM}$ IPTG (Isopropyl- $\beta$-D-Thiogalactopyranoside). To express the protein with isotope labels for NMR measurements, the cells were harvested before induction and the cell pellets from growth in $4 \mathrm{~L}$ with LB were resuspended in $1 \mathrm{~L} \mathrm{M} 9$-Minimal Media (containing $3 \mathrm{~g} / \mathrm{L}{ }^{12} \mathrm{C}$-Glucose and $1 \mathrm{~g} / \mathrm{L}^{15} \mathrm{NH} 4 \mathrm{Cl}$ for ${ }^{15} \mathrm{~N}$ labelling). The next step of expression was performed at $27^{\circ} \mathrm{C}$ and $140 \mathrm{rpm}$ over-night. The cells were, then, harvested and resuspended in $40 \mathrm{~mL}$ of cold PBS $\left(2 \mathrm{mM} \mathrm{KH}_{2} \mathrm{PO}_{4}, 8 \mathrm{mM} \mathrm{Na}_{2} \mathrm{HPO}_{4}, 2.5 \mathrm{mM} \mathrm{KCl}, 140 \mathrm{mM} \mathrm{NaCl}\right.$, 5 mM EDTA, pH 7.3) prior to cell lysis. The suspended cells were sonicated and warmed to $95^{\circ} \mathrm{C}$ and kept at that temperature for $10 \mathrm{~min}$. The lysate was spun down at 18,000 rpm and ammonium sulfate precipitation (saturation of 50\%) was carried out with the supernatant. The pellet was, finally, resuspended in PBS, diluted 1:2 with water to lower the salt concentration and the protein was separated by anion-exchange chromatography using a HiTrap Q column from GE healthcare. The column was equilibrated with PBS and a gradient of 30\% High-Salt Buffer (PBS containing $1 \mathrm{M} \mathrm{NaCl}$ ) was run for $20 \mathrm{~min}$ at a flow rate of $2 \mathrm{~mL} / \mathrm{min}$. The protein was exchanged to PBS buffer at pH 6.5 and concentrated using a centrifugal filter and the final concentration was measured by absorbance at $280 \mathrm{~nm}$. Protein purity was confirmed via SDS-PAGE. Quail osteopontin has a molecular weight of $24.3 \mathrm{kDa}$ and a calculated $\mathrm{pI}$ of 4.6 .

Methods. Synthesis of apatite in the presence ${ }^{15} \mathrm{~N}$ qOPN. Synthesis of the mineral in the presence of the protein was performed according to procedures published recently ${ }^{27,28}$. Briefly, hydroxyapatite was synthesized at $37^{\circ} \mathrm{C}$ and $\mathrm{pH} 9$ in the presence of $\left[\mathrm{U}_{-}{ }^{15} \mathrm{~N}(95 \%)\right] \mathrm{qOPN}$ (denoted as ${ }^{15} \mathrm{~N}$ qOPN) by titrating $16 \mathrm{ml}$ of $0.075 \mathrm{M}$ $\left(\mathrm{NH}_{4}\right)_{2} \mathrm{HPO}_{4}$ into $56 \mathrm{ml}$ of $0.040 \mathrm{M}$ calcium nitrate and $0.2 \mathrm{M}(0.8 \%)$ ammonium hydroxide solution in which $42.8 \mathrm{mg}$ of peptide were dissolved. Synthesis without ${ }^{15} \mathrm{~N}$ qOPN followed identical conditions without addition of the protein into the $\mathrm{Ca}\left(\mathrm{NO}_{3}\right)_{2}-\mathrm{NH}_{4} \mathrm{OH}$ solution. All syntheses were carried out under air. The titration was performed over duration of $5 \mathrm{~h}$ at a rate of $0.053 \mathrm{ml} / \mathrm{min}$ using a peristaltic pump. Solution was stirred at a rate of $156 \mathrm{rpm}$ with temperature held constant and $\mathrm{pH}$ corrected every $5 \mathrm{~min}$ by adding small aliquots of $24 \%$ ammonium hydroxide solution as necessary. After the phosphate solution was added, the temperature was set to $60{ }^{\circ} \mathrm{C}$ and the mixture stirred overnight. The solid precipitate was filtered and rinsed with double distilled water, 18.2 $\mathrm{M} \Omega(\mathrm{DDW})$. Excess water was removed from sediment by leaving the samples at $37^{\circ} \mathrm{C}$ for $60 \mathrm{~h}$. HAP and HAP. ${ }^{15} \mathrm{~N}$ qOPN crystals were pulverized in a porcelain mortar and stored as is. Similar procedures were used for synthesis of reference hydroxyapatite (without peptide).

Powder X-Ray Diffraction and crystallite size analysis. Powder X-ray diffractograms were recorded using a Cu $\mathrm{Ka}$ radiation source $(1.54 \AA$ ) on a Bruker AXS D8 Advance diffractometer. Measurements were performed on similar quantities of specimens in a $2 \theta$ range of $20^{\circ}-80^{\circ}$ for a duration of $0.05 \mathrm{~s}$. Size of crystallites were calculated using the Scherer equation with an angle of $25.9^{\circ}, \lambda=1.542 \AA$, a shape factor of 0.9 and using the reflection linewidth in the diffractograms.

Inductively coupled plasma (ICP) analysis. ICP analysis was performed using ULTIMA2 device from Jovin-Yvon-Horiba. Quantification of elemental calcium and phosphorous content in the materials was carried out by suspending $1 \mathrm{mg}$ of product powder in $10 \mathrm{ml}$ of $0.1 \mathrm{M} \mathrm{HCl}$ before injection to the plasma source. Relative errors in $\mathrm{Ca}$ and $\mathrm{P}$ measurements were used to determine errors in $\mathrm{Ca} / \mathrm{P}$ ratios. Relative error in these ratios for the two elements are between $0.65 \%$ and $1.07 \%$. ICP measurements of apatite mineral precipitated with other $\mathrm{NCPs}$ such as osteocalcin were done giving $\mathrm{Ca} / \mathrm{P}$ lower than 1.6 (data not shown) to verify that there is no bias the device used for the measurement in this work.

Elemental analysis. For carbon, hydrogen, nitrogen and sulfur elemental content analysis, $8 \mathrm{mg}$ of sample was introduced into a Thermo FlashEA 1112 Series analyzer. 
Brunauer-Emmett-Teller isotherm (BET). Surface area was measured on a NOVA 3200E Quantachrome Instruments surface area and pore size analyzer. Similar values of surface area were recorded for HAP, $69.2 \mathrm{mg}$ and for HAP·qOPN, $69.4 \mathrm{mg}$.

Transmission and Scanning Electron Microscopy (TEM and SEM). High-resolution TEM measurements were carried out on a JEM 2100, JEOL instrument with LaB6 e-beam source at acceleration voltages of $200 \mathrm{kV}$. Surface analysis of specimens were carried out on a FEI, Magellan 400L high-resolution SEM instrument. Prior to TEM measurements, specimens were immersed in ethanol, sonicated for $10 \mathrm{~min}$ and placed on copper grids until solvent had evaporated. For HRSEM, samples suspended in water were deposited on a double-sided $12 \mathrm{~mm}$ thick carbon tape.

Thermogravimetric Analysis (TGA). TGA measurements were carried out using $5 \mathrm{mg}$ of sample on a TGA Q500 TA Instruments analyzer. The temperature was first increased from room temperature at a heating rate of $10^{\circ} \mathrm{C} / \mathrm{min}$ to $120^{\circ} \mathrm{C}$, and left to anneal at $120^{\circ} \mathrm{C}$ for $30 \mathrm{~min}$. The weight loss was measured with a similar temperature gradient to $950{ }^{\circ} \mathrm{C}$.

NMR experiments. HAP. ${ }^{15} \mathrm{~N}$ qOPN and HAP samples were packed into $4 \mathrm{~mm}$ MAS NMR rotors. Most solidstate NMR experiments were carried out at room temperature on an $11.74 \mathrm{~T}$ Bruker Avance III spectrometer equipped with a $4 \mathrm{~mm}$ MAS VTN probe. The $2 \mathrm{D}{ }^{13} \mathrm{C}-{ }^{31} \mathrm{P}$ double $\mathrm{CP}$ experiments were performed on a $16.4 \mathrm{~T}$ Bruker Avance III spectrometer at Bruker Biospin in Rheinstetten, Germany. ${ }^{31} \mathrm{P}$ direct polarization (DP) experiments were performed using spinning rate of $10 \mathrm{kHz}, 2.5 \mu \mathrm{s}^{31} \mathrm{P} 90^{\circ}$ pulse and recycle delay of $40 \mathrm{~s} .{ }^{31} \mathrm{P}$ CPMAS experiments were carried out using a spinning rate of $10 \mathrm{kHz}$, a $2.6 \mu \mathrm{s}^{1} \mathrm{H} 90^{\circ}$ pulse, $3 \mathrm{~ms}$ contact pulse, SPINAL64 pulse scheme for proton decoupling ${ }^{71,72}$ and recycle delay of $1 \mathrm{~s}$. Slow spinning ${ }^{31} \mathrm{P}$ CPMAS experiments were performed at a spinning rate of $2 \mathrm{kHz}$ to extract CSA parameters. ${ }^{1} \mathrm{H}-{ }^{31} \mathrm{P}$ HETCOR experiments were performed using spinning rate of $10 \mathrm{kHz}$, a $2.55 \mu \mathrm{s}^{1} \mathrm{H} 90^{\circ}$ pulse, CP contact pulse of $3.5 \mathrm{~ms}$ and the PMLG5 scheme for ${ }^{1} \mathrm{H}$ homonuclear decoupling at an effective field of $120 \mathrm{kHz}$ during $\mathrm{t}_{1}{ }^{73,74}$. The two-pulse phase modulation TPPM pulse scheme was used for proton decoupling and the field used was $98 \mathrm{kHz}^{75}$. All HETCOR experiments employed a recycle delay of $0.7 \mathrm{~s} .{ }^{31} \mathrm{P}$ chemical shifts were calibrated relative to $\mathrm{H}_{3} \mathrm{PO}_{4}(85 \%)$. Signal to noise values in 2D HETCOR experiments were used as the basis for error bar calculations in CP build-up curves. 1D

${ }^{31} \mathrm{P}$ NMR data were processed using a $20 \mathrm{~Hz}$ line broadening exponential multiplication resulting in line widths that are $0.1 \mathrm{ppm}$ broader than the natural line width of peaks in the spectrum.

$2 \mathrm{D}^{31} \mathrm{P}{ }^{31} \mathrm{P}$ DARR measurements were performed at $10 \mathrm{kHz}$ using $2.5 \mu \mathrm{s}{ }^{1} \mathrm{H} 90^{\circ}$ pulse, contact pulse of $2 \mathrm{~ms}$, $500 \mathrm{~ms}$ of mixing time, SPINAL6 ${ }^{1} \mathrm{H}$ homonuclear decoupling and recycle delay of $2 \mathrm{~s}$.

$1 \mathrm{D}\left({ }^{31} \mathrm{P}\right.$ detected) CHHP measurements ${ }^{54}$ were performed using spinning rate of $10 \mathrm{kHz}, 2.75 \mu \mathrm{s}{ }^{1} \mathrm{H} 90^{\circ}$ pulse, $2 \mathrm{~ms}$ contact pulse between ${ }^{1} \mathrm{H}$ and ${ }^{13} \mathrm{C}$ in first and second $\mathrm{CP}$ periods, $5.3 \mu \mathrm{s}^{13} \mathrm{C} 90^{\circ}$ pulse, $20 \mathrm{~ms}$ z-filter time, $3 \mathrm{~ms}{ }^{1} \mathrm{H}-{ }^{31} \mathrm{P}$ cross polarization time, SPINAL64 ${ }^{1} \mathrm{H}$ homonuclear decoupling at a field of $80 \mathrm{kHz}$ with a recycle delay of $1 \mathrm{~s}$.

$2 \mathrm{D}^{31} \mathrm{P}-{ }^{13} \mathrm{C}$ double-CP experiments were performed at a spinning rate of $31 \mathrm{kHz}$ with an initial ${ }^{1} \mathrm{H}-{ }^{31} \mathrm{P}$ contact pulse of $5 \mathrm{~ms}$ using a ramped lock pulse on ${ }^{1} \mathrm{H}$ between 58 and $83 \mathrm{kHz}$ and a lock field of $36 \mathrm{kHz}$ on ${ }^{31} \mathrm{P}$, followed by a ${ }^{31} \mathrm{P}-{ }^{13} \mathrm{C}$ contact pulse of $16 \mathrm{~ms}$, using a ramped lock field on the ${ }^{13} \mathrm{C}$ between 36 and $40 \mathrm{kHz}$ and a lock field of $71 \mathrm{kHz}$ on ${ }^{31} \mathrm{P}$. A total of 24 points of ${ }^{31} \mathrm{P}$ evolution were collected in $\mathrm{t}_{1}$ with $16 \mathrm{k}$ repetitions of ${ }^{13} \mathrm{C}$ acquisition and a recycle delay of $2 \mathrm{~s}$. Processing of $2 \mathrm{D}$ involved no linear back-prediction, only exponential window function with $0.3 \mathrm{~Hz}$ and $20 \mathrm{~Hz}$ in $\mathrm{F} 1$ and $\mathrm{F} 2$ dimensions, respectively.

Rotor synchronized $2 \mathrm{D}^{31} \mathrm{P}_{-}{ }^{13} \mathrm{C} \mathrm{z}$-filtered TEDOR experiments were performed at a spinning rate of $10 \mathrm{kHz}$ with an initial ${ }^{1} \mathrm{H}-{ }^{31} \mathrm{P} \mathrm{CP}$ contact pulse of $2.5 \mathrm{~ms}$ and using $12 \mu \mathrm{s}^{13} \mathrm{C} 180^{\circ}$ pulses and $8 \mu \mathrm{s}^{31} \mathrm{P} 180^{\circ}$ pulses and twice shorter respective $90^{\circ}$ pulses on the two channels. Each of the two TEDOR recoupling periods in the experiment were $4.8 \mathrm{~ms}$ long. The $\mathrm{z}$-filter delays employed $10 \mathrm{kHz}$ irradiation on the protons for a duration of $2 \mathrm{~ms}$ each. Overall, $50 \mathrm{t}_{1}$ points were collected in the indirect dimension with 2048 repetitions and a recycle delay of $2 \mathrm{~s}$.

NMR simulations and data fitting. Chemical shift anisotropy of $14.8 \mathrm{kHz}$ and asymmetry of 1 were deduced from slow spinning ${ }^{31} \mathrm{P}$ CPMAS measurements by fitting the sideband patterns to simulated ones obtained using SIMPSON $^{76}$. These chemical shift parameters are similar to values measured for HAP before. Deconvolutions of ${ }^{31} \mathrm{P}$ lines were carried out using the DMFIT program developed by Massiot and co-workers ${ }^{57}$.

Received: 17 March 2020; Accepted: 7 September 2020

Published online: 24 September 2020

\section{References}

1. Mahamid, J. et al. Mapping amorphous calcium phosphate transformation into crystalline mineral from the cell to the bone in zebrafish fin rays. Proc. Natl. Acad. Sci. 107, 6316-6321 (2010).

2. Rey, C., Combes, C., Drouet, C. \& Glimcher, M. Bone mineral: update on chemical composition and structure. Osteoporos. Int. 20, 1013-1021 (2009).

3. Mroue, K. H. et al. High-resolution structural insights into bone: a solid-state NMR relaxation study utilizing paramagnetic doping. J. Phys. Chem. B 116, 11656-11661 (2012).

4. Mroue, K. H. et al. Acceleration of natural-abundance solid-state MAS NMR measurements on bone by paramagnetic relaxation from gadolinium-DTPA. J. Magn. Reson. 244, 90-97 (2014). 
5. Mroue, K. H. et al. Proton-detected solid-state NMR spectroscopy of bone with ultrafast magic angle spinning. Sci.Rep. 5, 1-10 (2015).

6. Xu, J. et al. Natural-abundance 43Ca solid-state NMR spectroscopy of bone. J. Am. Chem. Soc. 132, 11504-11509 (2010).

7. Zhu, P. et al. Time-resolved dehydration-induced structural changes in an intact bovine cortical bone revealed by solid-state NMR spectroscopy. J. Am. Chem. Soc. 131, 17064-17065 (2009).

8. Reznikov, N., Bilton, M., Lari, L., Stevens, M. M. \& Kröger, R. Fractal-like hierarchical organization of bone begins at the nanoscale. Science 360, eaao2189 (2018).

9. Wang, Y. et al. The predominant role of collagen in the nucleation, growth, structure and orientation of bone apatite. Nat. Mater. 11, 724-733 (2012).

10. Wang, Y. et al. Water-mediated structuring of bone apatite. Nat. Mater. 12, 1144-1153 (2013).

11. Tsortos, A. \& Nancollas, G. H. The role of polycarboxylic acids in calcium phosphate mineralization. J. Colloid Interface Sci. 250, 159-167 (2002).

12. Sugino, A., Miyazaki, T. \& Ohtsuki, C. Apatite-forming ability of polyglutamic acid hydrogels in a body-simulating environment. J. Mater. Sci. Mater. Med. 19, 2269-2274 (2008).

13. Wazen, R. M. et al. In vivo functional analysis of polyglutamic acid domains in recombinant bone sialoprotein. J. Histochem. Cytochem. 55, 35-42 (2007).

14. Nudelman, F. et al. The role of collagen in bone apatite formation in the presence of hydroxyapatite nucleation inhibitors. Nat. Mater. 9, 1004-1009 (2010).

15. Fujisawa, R. \& Kuboki, Y. Affinity of bone sialoprotein and several other bone and dentin acidic proteins to collagen fibrils. Calcif. Tissue Int. 51, 438-442 (1992).

16. Neary, M. T. et al. Contrasts between organic participation in apatite biomineralization in brachiopod shell and vertebrate bone identified by nuclear magnetic resonance spectroscopy. J. R. Soc. Interface 8, 282-288 (2011).

17. Rodriguez, D. E. et al. Multifunctional role of osteopontin in directing intrafibrillar mineralization of collagen and activation of osteoclasts. Acta Biomater. 10, 494-507 (2014)

18. Hu, Y., Rawal, A. \& Schmidt-Rohr, K. Strongly bound citrate stabilizes the apatite nanocrystals in bone. Proc. Natl. Acad. Sci. USA 107, 22425-22429 (2010).

19. Davies, E. et al. Citrate bridges between mineral platelets in bone. Proc. Natl. Acad. Sci. USA 111, E1354-E1363 (2014).

20. Reid, D. et al. Citrate occurs widely in healthy and pathological apatitic biomineral: mineralized articular cartilage, and intimal atherosclerotic plaque and apatitic kidney stones. Calcif. Tissue Int. 93, 253-260 (2013).

21. Liu, Y., Luo, D. \& Wang, T. Hierarchical structures of bone and bioinspired bone tissue engineering. Small 12, 4611-4632 (2016).

22. Hunter, G. K., Hauschka, P. V., Poole, A. R., Rosenberg, L. C. \& Goldberg, H. A. Nucleation and inhibition of hydroxyapatite formation by mineralized tissue proteins. Biochem. J. 317, 59-64 (1996).

23. Sodek, J., Ganss, B. \& McKee, M. Osteopontin. Crit. Rev. Oral Biol. Med. 11, 279-303 (2000).

24. Arachchige, R. J. et al. Solid-state NMR identification of intermolecular interactions in amelogenin bound to hydroxyapatite. Biophys. J. 115, 1666-1672 (2018).

25. Du, Y.-P. et al. Study of binding interaction between Pif80 protein fragment and aragonite. Sci. Rep. 6, 30883 (2016).

26 Iline-Vul, T. et al. How does osteocalcin lacking $\gamma$-glutamic groups affect biomimetic apatite formation and what can we say about its structure in mineral-bound form?. J. Struct. Biol. 207, 104 (2019).

27. Iline-Vul, T., Matlahov, I., Grinblat, J., Keinan-Adamsky, K. \& Goobes, G. Changes to the disordered phase and apatite crystallite morphology during mineralization by an acidic mineral binding peptide from osteonectin. Biomacromolecules 16, 2656-2663 (2015).

28. Matlahov, I. et al. Interfacial mineral-peptide properties of a mineral binding peptide from osteonectin and bone-like apatite. Chem. Mater. 27, 5562-5569 (2015).

29 Iline-Vul, T. et al. Understanding the roles of functional peptides in designing apatite and silica nanomaterials biomimetically using NMR techniques. Curr. Opin. Colloid Interface Sci. 33, 44 (2018).

30. George, A. \& Veis, A. Phosphorylated proteins and control over apatite nucleation, crystal growth, and inhibition. Chem. Rev. 108, 4670-4693 (2008).

31. Lenton, S. et al. Effect of phosphorylation on a human-like osteopontin peptide. Biophys. J. 112, 1586-1596 (2017).

32. Gericke, A. et al. Importance of phosphorylation for osteopontin regulation of biomineralization. Calcif. Tissue Int. 77, 45-54 (2005)

33. O'Regan, A. W. et al. Osteopontin is associated with T cells in sarcoid granulomas and has T cell adhesive and cytokine-like properties in vitro. J. Immunol. 162, 1024-1031 (1999).

34. Agnholt, J. et al. Osteopontin, a protein with cytokine-like properties, is associated with inflammation in Crohn's disease. Scand. J. Immunol. 65, 453-460 (2007).

35. Morinobu, M. et al. Osteopontin expression in osteoblasts and osteocytes during bone formation under mechanical stress in the calvarial suture in vivo. J. Bone Miner. Res. 18, 1706-1715 (2003).

36. Hunter, G. K., O'Young, J., Grohe, B., Karttunen, M. \& Goldberg, H. A. The flexible polyelectrolyte hypothesis of protein-biomineral interaction. Langmuir 26, 18639-18646 (2010).

37. Hunter, G. K. Role of osteopontin in modulation of hydroxyapatite formation. Calcif. Tissue Int. 93, 348-354 (2013).

38. Ravindran, S. \& George, A. Multifunctional ECM proteins in bone and teeth. Exp. Cell Res. 325, 148-154 (2014).

39. Addison, W. N., Masica, D. L., Gray, J. J. \& McKee, M. D. Phosphorylation-dependent inhibition of mineralization by osteopontin ASARM Peptides Is regulated by PHEX cleavage. J. Bone Miner. Res. 25, 695-705 (2010).

40. Martin, A. et al. Degradation of MEPE, DMP1, and release of SIBLING ASARM-Peptides (Minhibins): ASARM-peptide(s) are directly responsible for defective mineralization in HYP. Endocrinology 149, 1757-1772 (2008).

41. Li, S. Y. \& Wang, L. J. Phosphorylated osteopontin peptides inhibit crystallization by resisting the aggregation of calcium phosphate nanoparticles. CrystEngComm 14, 8037-8043 (2012).

42 de Bruyn, J. R. et al. Dynamic light scattering study of inhibition of nucleation and growth of hydroxyapatite crystals by osteopontin. PLOS ONE 8, e56764 (2013).

43. Li, S. Y., Wu, S. S., Nan, D. F., Zhang, W. J. \& Wang, L. J. Inhibition of pathological mineralization of calcium phosphate by phosphorylated osteopontin peptides through step-specific interactions. Chem. Mater. 26, 5605-5612 (2014).

44. Klaning, E., Christensen, B., Sorensen, E., Vorup-Jensen, T. \& Jensen, J. Osteopontin binds multiple calcium ions with high affinity and independently of phosphorylation status. Bone 66, 90-95 (2014).

45. Pampena, D. et al. Inhibition of hydroxyapatite formation by osteopontin phosphopeptides. Biochem. J. 378, 1083-1087 (2004).

46. Silverman, L. et al. Hydroxyapatite growth inhibition by osteopontin hexapeptide sequences. Langmuir 26, 9899-9904 (2010).

47. Fisher, L. W., Torchia, D. A., Fohr, B., Young, M. F. \& Fedarko, N. S. Flexible structures of SIBLING proteins, bone sialoprotein, and osteopontin. Biochem. Biophys. Res. Commun. 280, 460-465 (2001).

48. Dyson, H. J. \& Wright, P. E. Intrinsically unstructured proteins and their functions. Nat. Rev. Mol. Cell Biol. 6, 197-208 (2005).

49. Boskey, A. L. \& Villarreal-Ramirez, E. Intrinsically disordered proteins and biomineralization. Matrix Biol. 52-54, 43-59 (2016).

50. Kurzbach, D. et al. Cooperative unfolding of compact conformations of the intrinsically disordered protein osteopontin. Biochemistry 52, 5167-5175 (2013). 
51. Konrat, R. NMR contributions to structural dynamics studies of intrinsically disordered proteins. J. Magn. Reson. 241, 74-85. https://doi.org/10.1016/j.jmr.2013.11.011 (2014).

52. Platzer, G. et al. The metastasis-associated extracellular matrix protein osteopontin forms transient structure in ligand interaction sites. Biochemistry 50, 6113-6124 (2011).

53. Thurner, P. J. et al. Osteopontin deficiency increases bone fragility but preserves bone mass. Bone 46, 1564-1573 (2010).

54. Poundarik, A. A. et al. Dilatational band formation in bone. Proc. Natl. Acad. Sci. USA 109, 19178-19183 (2012).

55 Nikel, O. E., Laurencin, D., McCallum, S. A., Gundberg, C. M. \& Vashishth, D. NMR investigation of the role of osteocalcin and osteopontin at the organic-inorganic interface in bone. Langmuir 29, 13873-13882 (2013).

56. Ibsen, C. J. S., Gebauer, D. \& Birkedal, H. Osteopontin stabilizes metastable states prior to nucleation during apatite formation. Chem. Mater. 28, 8550-8555 (2016).

57. Massiot, D. et al. Modelling one- and two-dimensional solid-state NMR spectra. Magn. Reson. Chem. 40, 70-76 (2002).

58. Jäger, C., Welzel, T., Meyer-Zaika, W. \& Epple, M. A solid-state NMR investigation of the structure of nanocrystalline hydroxyapatite. Magn. Reson. Chem. 44, 573-580 (2006).

59. Mathew, R. et al. Solid-state 31P and $1 \mathrm{H}$ NMR investigations of amorphous and crystalline calcium phosphates grown biomimetically from a mesoporous bioactive glass. J. Phys. Chem. C 115, 20572-20582 (2011).

60. Morag, O., Abramov, G. \& Goldbourt, A. Complete chemical shift assignment of the ssDNA in the filamentous bacteriophage fd reports on its conformation and on its interface with the Capsid Shell. J. Am. Chem. Soc. 136, 2292-2301 (2014).

61. Jaroniec, C. P., Filip, C. \& Griffin, R. G. 3D TEDOR NMR experiments for the simultaneous measurement of multiple carbonnitrogen distances in uniformly 13C, 15N-labeled solids. J. Am. Chem. Soc. 124, 10728-10742 (2002).

62. Goldsmith, H. et al. Homotypic interactions of soluble and immobilized osteopontin. Ann. Biomed. Eng. 30, 840-850 (2002).

63. Kourkoumelis, N., Balatsoukas, I. \& Tzaphlidou, M. Ca/P concentration ratio at different sites of normal and osteoporotic rabbit bones evaluated by Auger and energy dispersive X-ray spectroscopy. J. Biol. Phys. 38, 279-291 (2012).

64. Davies, E. et al. $\mathrm{Ca} / \mathrm{P}$ concentration ratio at different sites of normal and osteoporotic rabbit bones evaluatedCitrate bridges between mineral platelets in bone. Proc. Natl. Acad. Sci. USA 111, E1354-E1363 (2014).

65. Raghunathan, V. et al. Homonuclear and heteronuclear NMR studies of a statherin fragment bound to hydroxyapatite crystals. J. Phys. Chem. B 110, 9324-9332 (2006).

66 Athanasiadou, D. et al. Nanostructure, osteopontin, and mechanical properties of calcitic avian eggshell. Sci. Adv. 4, eaar3219 (2018).

67. Rohl, C. A., Strauss, C. E. M., Misura, K. M. S. \& Baker, D. Protein structure prediction using rosetta. Numer. Comput. Methods Pt D 383, 66-93 (2004).

68. Roehrich, A. \& Drobny, G. Solid-state NMR studies of biomineralization peptides and proteins. Acc. Chem. Res. 46, 2136-2136 (2013).

69. Shaw, W. Solid-state NMR studies of proteins immobilized on inorganic surfaces. Solid State Nucl. Magn. Reson. 70, 1-14 (2015).

70. Mateos, B. et al. The ambivalent role of proline residues in an intrinsically disordered protein: from disorder promoters to compaction facilitators. J. Mol. Biol. 432, 3093-3111 (2020).

71. Fung, B., Khitrin, A. \& Ermolaev, K. An improved broadband decoupling sequence for liquid crystals and solids. J. Magn. Reson. 142, 97-101 (2000).

72. Brauniger, T., Wormald, P. \& Hodgkinson, P. Improved proton decoupling in NMR spectroscopy of crystalline solids using the SPINAL-64 sequence. Monatshefte Fur Chemie 133, 1549-1554 (2002).

73. Vinogradov, E., Madhu, P. \& Vega, S. A bimodal Floquet analysis of phase modulated Lee-Goldburg high resolution proton magic angle spinning NMR experiments. Chem. Phys. Lett. 329, 207-214 (2000).

74. Vinogradov, E., Madhu, P. \& Vega, S. High-resolution proton solid-state NMR spectroscopy by phase-modulated Lee-Goldburg experiment. Chem. Phys. Lett. 314, 443-450 (1999).

75. Bennett, A., Rienstra, C., Auger, M., Lakshmi, K. \& Griffin, R. Heteronuclear decoupling in rotating solids. J. Chem. Phys. 103, 6951-6958 (1995).

76. Bak, M., Rasmussen, J. \& Nielsen, N. SIMPSON: A general simulation program for solid-state NMR spectroscopy. J. Magn. Reson. 147, 296-330 (2000).

\section{Acknowledgements}

The authors thank Dr Yuval Elias and Professor Lia Addadi for critical reading of the manuscript. This work was funded by the Israel Science Foundation grants \#1917/17 and \#2104/20.

\section{Author contributions}

T.I.-V. and S.H. synthesized biomimetic apatite with and without OPNT.I-V. performed the XRD, TGA-MS, ICPT-I.-V. and K. K.-A. performed 2D HETCOR, 2D DARR and CHHP measurementsR.N. and I.M. ran 2D z-filtered TEDOR measurementsI.P. performed TEM measurements and analysisG.A.-O. performed DCP measurementsB.M. helped write the MSB.M and R.K. expressed labelled OPN proteinT. I-V., R.N and G.G wrote the MS.

\section{Competing interests}

The authors declare no competing interests.

\section{Additional information}

Supplementary information is available for this paper at https://doi.org/10.1038/s41598-020-72786-X.

Correspondence and requests for materials should be addressed to G.G.

Reprints and permissions information is available at www.nature.com/reprints.

Publisher's note Springer Nature remains neutral with regard to jurisdictional claims in published maps and institutional affiliations. 
(c) (i) Open Access This article is licensed under a Creative Commons Attribution 4.0 International cc) License, which permits use, sharing, adaptation, distribution and reproduction in any medium or format, as long as you give appropriate credit to the original author(s) and the source, provide a link to the Creative Commons licence, and indicate if changes were made. The images or other third party material in this article are included in the article's Creative Commons licence, unless indicated otherwise in a credit line to the material. If material is not included in the article's Creative Commons licence and your intended use is not permitted by statutory regulation or exceeds the permitted use, you will need to obtain permission directly from the copyright holder. To view a copy of this licence, visit http://creativecommons.org/licenses/by/4.0/.

(C) The Author(s) 2020 